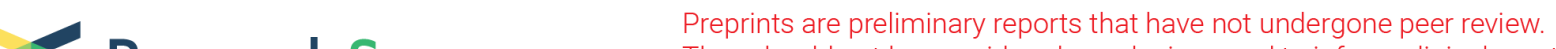 $\begin{array}{ll}\text { Research Square } & \text { They should not be considered conclusive, used to inform clinical practice, } \\ \text { or referenced by the media as validated information. }\end{array}$
}

\section{A $\beta$-Induced Damage Memory in hCMEC/D3 Cell Mediated by Sirtuin-1}

Haochen Liu

China Pharmaceutical university

Yixuan Zhang

China pharmaceutical university

Hong Zhang

China Pharmaceutical university

Sheng $\mathrm{Xu}$

China Pharmaceutical university

Huimin Zhao

China Pharmaceutical university

Xiaoquan liu ( $\sim$ lxq@cpu.edu.cn )

China pharmaceutical university

\section{Research}

Keywords: cerebrovascular endothelial damage memory, sirt-1, vicious circle, kinetics process modeling, Alzheimer's disease

Posted Date: August 25th, 2020

DOI: https://doi.org/10.21203/rs.3.rs-61654/v1

License: (c) (i) This work is licensed under a Creative Commons Attribution 4.0 International License. Read Full License

Version of Record: A version of this preprint was published at International Journal of Molecular Sciences on November 3rd, 2020. See the published version at https://doi.org/10.3390/ijms21218226. 
3 Authors: HaoChen $\mathrm{Liu}^{1 \#}{ }^{1 \#}$, Yixuan Zhang ${ }^{1 \#}$, Hong Zhang ${ }^{1}$, Sheng $\mathrm{Xu}^{1}$, Huimin Zhao ${ }^{1}$,

$4 \quad$ XiaoQuan $\mathrm{Liu}^{1, *}$

$5 \quad$ * Corresponds author

$6 \quad$ \# these two authors have equal contribution to the manuscript.

7 Address:

$8 \quad{ }^{1}$ Center of Drug Metabolism and Pharmacokinetics, China Pharmaceutical

$9 \quad$ University, Nanjing, 210009, China

Tel.: + 86-25-83271260

11 E-Mail address: haochenliu@cpu.edu.cn (HCL); yxzhang@stu.cpu.edu.cn (YXZ);

12 296481679@qq.com (HZ); 570302057@qq.com (SX); 1060046870@qq.com (HMZ)

$131 x q @$ cpu.edu.cn (XQL, Corresponds author). 


\section{Abstract}

Background: It is well accepted that accumulation of beta-amyloid (A $\beta)$ may involve in endothelial dysfunction during the Alzheimer's disease (AD) progression. However, anti- $A \beta$ antibodies, which remove $A \beta$ plaques, do not improve cerebrovascular function in $\mathrm{AD}$ animal models. The reasons for these paradoxical results still remain to be further investigated. We hypothesize that $A \beta$ exposure may cause persistent damage to cerebral endothelial cell even after $A \beta$ is removed (termed as cerebrovascular endothelial damage memory). The aim of this study is to investigate whether cerebrovascular endothelial damage memory exists in endothelial cells.

Method: The hCMEC/D3 cells are treated with $A \beta_{1-42}$ for $12 \mathrm{~h}$ and then withdraw $A \beta_{1-42}$ for another $12 \mathrm{~h}$ incubation to investigate whether cerebrovascular endothelial damage memory exists in endothelial cells. A mechanism based kinetics progression model is developed to investigate the dynamic characters of the cerebrovascular endothelial damage.

Results: After $A \beta_{1-42}$ was removed, the level of sirt-1 recovered but the cell vitality did not improved which suggested that the cerebrovascular endothelial damage memory may exist in endothelial cells. Sirt-1 activator SRT2104 and NAD ${ }^{+}$ supplement may relieve the cerebrovascular endothelial damage memory dose dependently. sirt-1 inhibitor EX527 may exacerbate the cerebrovascular endothelial damage memory. Kinetics analysis suggested that sirt-1 involves in initiating the cerebrovascular endothelial damage memory otherwise $\mathrm{NAD}^{+}$exhaustion plays a vital role in maintaining the cerebrovascular endothelial damage memory.

Conclusions: This study provides a novel feature of cerebrovascular endothelial damage induced by $A \beta$.

Key words: cerebrovascular endothelial damage memory; sirt-1; vicious circle;

\section{kinetics process modeling; Alzheimer's disease}

\section{Background}

Dementia is considered as one of the biggest threats to the aging population and a major public health problem worldwide, whose leading cause Alzheimer's disease (AD) accounts for about $80 \%$ dementia [1]. Previous researches proposed a amyloid 
cascade hypothesis which suggested that amyloid $\beta$ (A $\beta)$ plays a central role in the development of $\mathrm{AD}[2,3]$. Therefore, according to the hypothesis, multiple anti-bodies targeted at $A \beta$ (e.g. Solanezumab, Bapineuzumab and Crenezumab, etc) are tested in AD patients [4]. Unfortunately, none of these anti-bodies exhibits efficacy in clinical trails [5].

An often-cited explanation for the failure of anti-bodies targeted at $A \beta$ in clinical trials is that they are set too late in the disease process $[5,6]$. However, there is a different opinion on the explanation for anti-A $\beta$ immunotherapies lacking efficacy. It is widely accepted that cerebrovascular system may play an important role in $A \beta$ clearance [7]. Therefore, Q $i$ et al suggested that the failure of anti- $A \beta$ immunotherapies may be due to the cerebrovascular damage which can not be improved by removing $A \beta$ [8]. Previous reports could provide more evidences for this hypothesis. When the AD animal models are treated with anti-A $\beta$ antibodies, they are effective at removing the $A \beta$ plaques, but void at preventing hemorrhages which may be related to the cerebrovascular damage [9-12]. In other words, $A \beta$ may impair the cerebrovascular function, but the cerebrovascular function can not be improved by removing $A \beta$ [10]. Therefore, to provide a new insight into the failure of anti-A $\beta$ immunotherapies, it is necessary to investigate the reasons for lacking efficacy of removing $A \beta$ on cerebrovascular function improvement.

Diabetes "metabolic memory" phenomenon may provide enlightenments for the investigation on the persistent endothelial dysfunction of AD. Metabolic memory phenomenon is defined as the persistence of diabetes complications even after glycemic control has been pharmacologically achieved [13]. Especially, the Metabolic memory phenomenon is associated to the endothelial dysfunction [14]. In other word, the endothelial dysfunction induced by hyperglycemia in the early stage of diabetes might not be improved by the following glycemic control. The endothelial dysfunction which can not be improved by removing $A \beta$ seems to be similar to the metabolic memory phenomenon of diabetes. Therefore, it is reasonable to assume that the damage memory phenomenon may exist in cerebrovascular endothelial cell. 
observed in $\mathrm{AD}$ patients, it is reasonable to assume that the epigenetic factors may involve in the formation of cerebrovascular endothelial damage memory $[15,16]$. The Epigenetic factors include DNA methylation, histone modifications, chromatin remodeling, and regulation by non-coding RNA [15]. Among these factors, histone modifications variations are observed in wide range of researches involving in $\mathrm{AD}$ patients, $\mathrm{AD}$ animal models, and $\mathrm{AD}$ culture models, which suggests that histone modifications may play a vital role in the development of $\mathrm{AD}[15,17]$. Histone modifications include multiple types e.g. acetylation, methylation, phosphorylation, ubiquitination, etc., among which acetylation is the most ubiquitous and well studied $[15,17]$. Histone acetylation is catalyzed by histone acetyltransferase (HAT) while deacetylation is influenced by histone deacetylases (HDAC) [15]. Among these HDAC enzymes, sirt-1, which decreases significantly in AD patients, is closely associated with the proliferation and apoptosis of endothelial cells [18, 19]. Therefore, sirt-1 may be related to the formation of $\mathrm{AD}$ cerebrovascular endothelial damage memory.

The aim of this study is to investigate that whether the damage memory process may exist in cerebrovascular endothelial cells and the kinetics characters of this process. A mechanism based kinetic progression model is developed to investigate the dynamic process of cerebrovascular endothelial cell damage as well as the method for improving the cerebrovascular endothelial cell damage memory. Our research provides new insight into the AD cerebrovascular endothelial cell dysfunction and the new idea for the improvement of cerebrovascular endothelial function.

\section{Result}

\section{Withdrawing A $\beta$ does not improve hCMEC/D3 cell vitality}

The results (Fig. 1E) show that the cell vitality in $A \beta$ group decreases during $\mathrm{A} \beta_{1-42}$ incubation. After $\mathrm{A} \beta_{1-42}$ is withdrawn, the cell vitality in the damage memory group did not recover and there was no significant difference $(P>0.05, t=0.28$, t-test) compared with $A \beta$ group. These results suggested that the damage memory may exist in endothelial cell. In other words, if endothelial cell exposes to $A \beta_{1-42}$ for a certain time, the damage induced by $A \beta_{1-42}$ may not be improved by 
withdrawing $A \beta_{1-42}$. Furthermore, Our result (Fig. 1A-D) suggested that sirt-1 level decreased during $A \beta_{1-42}$ incubation and its level recovered when $A \beta_{1-42}$ is withdrawn. Meanwhile the levels of $\mathrm{NAD}^{+}$and MMP decreased whereas $\mathrm{p}^{\mathrm{SHC}}$ and ROS increased continually in both $A \beta$ group and damage memory group. Compared with control group, $\mathrm{NAD}^{+}$, p66 ${ }^{\mathrm{SHC}}$, ROS, Sirt-1 activity and MMP had significant difference $\left(\mathrm{p}_{\mathrm{NAD}^{+}}<0.05, \mathrm{t}_{\mathrm{NAD}^{+}}=-4.97 ; \mathrm{p}_{p 66}\right.$ SHC $<0.05, \mathrm{t}_{p 66^{S H C}}=4.88$; $\mathrm{p}_{\mathrm{MMP}}<0.05, \mathrm{t}_{\mathrm{MMP}}=-7.24 ; p_{R O S}<0.01, t_{R O S}=4.57 ; p_{\text {sirt }}<0.01, t_{\text {sirt }}=-6.33$, t-test) in both $\mathrm{A} \beta$ group and damage memory at $24 \mathrm{~h}$. But $\mathrm{NAD}^{+}, \mathrm{p} 66^{\mathrm{SHC}}, \mathrm{ROS}$, Sirt-1 activity and MMP had no significant difference $\left(\mathrm{p}_{\mathrm{NAD}^{+}}>0.05, \mathrm{t}_{\mathrm{NAD}^{+}}=1.50\right.$; $\mathrm{p}_{p 66}$ SHC $>0.05, \mathrm{t}_{p 66}$ SHC $=0.08 ; \mathrm{p}_{\mathrm{MMP}}>0.05, \mathrm{t}_{\mathrm{MMP}}=0.98 ; p_{R O S}>0.05$, $t_{R O S}=-0.77 ; p_{\text {sirt }}>0.05, t_{\text {sirt }}=-1.09$, t-test) between $\mathrm{A} \beta$ group and damage memory at $24 \mathrm{~h}$. Our study suggested that when hCMEC/D3 cell exposes to $A \beta_{1-42}$ for $12 \mathrm{~h}$, the levels of $\mathrm{NAD}^{+}, \mathrm{p} 66^{\mathrm{SHC}}$, ROS, and MMP may alter and the variation of their levels can not recover to the baseline level. To determine whether intracellular A $\beta$ accumulation involves in the formation of damage memory, we performed western blot to measure the intracellular A $\beta$ level after hCMEC/D3 cells are exposed to $A \beta$ for $24 \mathrm{~h}$. The results (the brands are given in supplementary materials) suggested that no intracellular $A \beta$ accumulation are detected. Therefore, it seems that intracellular $\mathrm{A} \beta$ accumulation may not invovle in the formation of damge memory.

\section{Stimulating sirt-1 relieves the endothelial damage memory}

As the expression of sirt- 1 alters in the damage memory group compared to the control group, sirt-1 may affect the formation of the endothelial damage memory. There are two ways to stimulate the activity of sirt-1. Firstly, selective small molecule activator of sirt-1 SRT2104 is available to increase sirt-1 activity. Secondly, as NAD ${ }^{+}$ is a vital cofactor of sirt- $1, \mathrm{NAD}^{+}$supplement also can stimulate the activity of sirt-1. Therefore, both methods are used to test whether the activity of sirt-1 may affect the formation of the endothelial damage memory. In the first experiment, a sirt-1 activator SRT2104 is used to stimulate sirt-1 activity. The results are shown in Fig4. A. Compared with the damage memory group, the levels of $\mathrm{NAD}^{+}, \mathrm{MMP}, \mathrm{Mn}-\mathrm{SOD}$ and 
cell vitality in SRT2104 treated groups increased significantly $\left(\mathrm{p}_{\mathrm{NAD}^{+}}<0.05\right.$, $\mathrm{t}_{\mathrm{NAD}^{+}}=17.35 ; \mathrm{p}_{\mathrm{MMP}}<0.05, \quad \mathrm{t}_{\mathrm{MMP}}=11.29 ; \mathrm{p}_{\mathrm{MTT}}<0.05, \quad \mathrm{t}_{\mathrm{MTT}}=31.53 ;$ $p_{S O D}<0.01, t_{S O D}=10.41$, t-test $)$ meanwhile $\mathrm{p}^{\mathrm{SHC}}$ and ROS decreased significantly $\left(p_{p 66}<0.05, t_{p 66}=-11.01 ; p_{R O S}<0.01, t_{R O S}=-5.04, \mathrm{t}\right.$-test $)$. The variations of above biomarkers levels are dose dependent. Therefore, our reults suggested that stimulating sirt-1 relieve the endothelial damage memory.

In the second experiment, $\mathrm{NAD}^{+}$supplement is used to increase the activity of sirt-1. The results are represented in Fig. 2C. Compared with memory group, the levels of Mn-SOD, MMP and cell vitality in $\mathrm{NAD}^{+}$treated groups increased significantly $\left(p_{S O D}<0.05, t_{S O D}=2.68 ; \mathrm{p}_{\mathrm{MMP}}<0.05, \mathrm{t}_{\mathrm{MMP}}=3.61 ; \mathrm{p}_{\mathrm{MTT}}<\right.$ $0.05, \mathrm{t}_{\mathrm{MTT}}=9.11$, t-test) meanwhile $\mathrm{p} 66^{\mathrm{SHC}}$ and $\mathrm{ROS}$ decreased significantly $\left(p_{p 66}<0.05, t_{p 66}=-8.94 ; p_{R O S}<0.01, t_{R O S}=-11.89\right.$ t-test $)$. The variations of above the biomarkers levels are dose dependent. Therefore, our reults suggested that $\mathrm{NAD}^{+}$supplement relieves the endothelial damage memory.

\section{Inhibiting sirt-1 exacerbates the endothelial damage memory}

Stimulating sirt-1 may relieve the endothelial damage memory, whereas inhibiting sirt-1 may exacerbate the endothelial damage memory presumably. To test this hypothesis, a sirt-1 inhibitor EX527 is used in the cell experiment. The results are shown in Fig 4B. Compared with the damage memory group, the levels of Mn-SOD, $\mathrm{NAD}^{+}, \mathrm{MMP}$ and cell vitality in EX527 treated groups decreased significantly $\left(p_{S O D}<0.01, t_{S O D}=-14.00 ; \mathrm{p}_{\mathrm{NAD}^{+}}<0.05, \mathrm{t}_{\mathrm{NAD}^{+}}=-29.89, \mathrm{p}_{\mathrm{MMP}}<0.05\right.$, $\mathrm{t}_{\mathrm{MMP}}=-14.52, \mathrm{p}_{\mathrm{MTT}}<0.05, \mathrm{t}_{\mathrm{MTT}}=-40.11$, t-test) meanwhile $\mathrm{p}^{\mathrm{SHC}}$ and ROS increased significantly $\left(p_{p 66}<0.05, t_{p 66}=24.03 ; p_{R O S}<0.01, t_{R O S}=39.27, \mathrm{t}\right.$-test $)$. The variations of the above biomarkers levels are dose dependent. Therefore, our reults suggested that inhibiting sirt-1 exacerbates the endothelial damage memory. The dysfunction of sirt-1 may not only increase the production of ROS but also impair the elimination of ROS.

$\mathrm{NAD}^{+}$and sirt-1 play different roles in the dynamic process of endothelial damage memory

We wonder that whether $\mathrm{NAD}^{+}$and sirt-1 may play different roles in the 
endothelial damage memory kinetic process. To test this hypothesis , a mechanism based kinetic progression model is developed. The visual predictive check (VPC) for this model is represented in Fig. 3. The VPC plots show that the observed average data falls within $95 \%$ prediction confidence interval. The bootstrapping values of estimated model parameters (table 1) remain near the final parameters estimation with relative low coefficient of variances $(\mathrm{CV})$. Therefore, the goodness of fit for the mechanism based kinetic progression model is satisfactory.

After the internal validation of the mechanism based kinetic progression is performed, simulations based on this model are conducted. The simulations are performed based on three scenario. The aim for the first scenario is to investigate the time of endothelial damage memory formation. The relevance of this simulation is to provide a baseline data for comparing the effects of different levels of sirt-1 and $\mathrm{NAD}^{+}$on the time of endothelial damage memory formation. The results of the first simulation are shown in the Fig. 4. The results suggested that when the cells are treated with $\mathrm{A} \beta_{1-42}$ for more than $4 \mathrm{~h}$, the levels of sirt-1, Sirt-1 activity, p $66^{\mathrm{SHC}}$, ROS, NAD ${ }^{+}, \mathrm{MMP}$ and cell vitality may not be recovered by withdrawing $A \beta_{1-42}$. In other words, the baseline of endothelial damage memory formation time might be 4h post $A \beta_{1-42}$ treatment in hCMEC/D3 cells. After the base line time of endothelial damage memory formation is determined, the simulation of the second scenario is performed. In this scenario, the level of sirt- 1 or $\mathrm{NAD}^{+}$is changed and then the time of endothelial damage memory formation is estimated. The results of above simulation are shown in Fig. 5. Changing the levels of both sirt-1 and $\mathrm{NAD}^{+}$may alter the time of endothelial damage memory formation. Particularly the variation of the endothelial damage memory formation time is more sensitive to changing of the sirt-1 level than that of the $\mathrm{NAD}^{+}$level. In the third scenario, the methods for relieving the endothelial damage memory were investigated. The effects of sirt-1 activator or $\mathrm{NAD}^{+}$supplement on relieving the endothelial damage memory were estimated. The results of the above simulation are shown in Fig. 6. When the cells are treated with sirt-1 activator, the time of endothelial damage memory formation is delayed to $6 \mathrm{~h}$ post $\mathrm{A} \beta_{1-42}$ incubation. When the cells are treated with $\mathrm{NAD}^{+}$supplement, the time 
194 of endothelial damage memory formation is delayed to $8 \mathrm{~h}$ post $A \beta_{1-42}$ incubation.

195 These results suggested that $\mathrm{NAD}^{+}$supplement may be a potential method for 196 delaying the formation of endothelial damage memory.

\section{Different roles of $\mathrm{NAD}^{+}$and sirt-1 in delaying the formation of endothelial damage memory}

As the above simulations suggested that the $\mathrm{NAD}^{+}$supplement may delay the formation of endothelial damage memory, cell experiments are performed to test this hypothesis. To test that whether $\mathrm{NAD}^{+}$supplement can delay the formation of endothelial damage memory, the baseline time of endothelial damage memory formation should be determined. The above simulation suggested that the baseline time for endothelial damage memory formation may be $4 \mathrm{~h}$ after $2.5 \mu \mathrm{mol} / \mathrm{ml} \quad \mathrm{A} \beta_{1-42}$ incubation. Therefore, the cell experimets are designed to investigate the baseline time of the damage memory formation and whether different $A \beta_{1-42}$ concentrations affect the baseline time (Fig. 7A). The cell vitality in $2 \mathrm{~h}$ memory group recovered whereas it did not relive in $4 \mathrm{~h}$ memory group after $\mathrm{A} \beta(2.5 \mu \mathrm{mol} / \mathrm{ml})$ is withdrawn (Fig. 7B).

Compared with $\mathrm{A} \beta(2.5 \mu \mathrm{mol} / \mathrm{ml})$ group, the cell vitality in $2 \mathrm{~h}$ memory group had significant difference $(\mathrm{p}<0.05, \mathrm{t}=1.81$, $\mathrm{t}$-test $)$ but it had no significant difference ( $>0.05, t=1.48, t-t e s t$ ) in $4 \mathrm{~h}$ memory group (Fig. 7B). The results suggested that the baseline time of endothelial damage memory formation might be $4 \mathrm{~h}$ after $A \beta_{1-42}$ $(2.5 \mu \mathrm{mol} / \mathrm{ml})$ incubation. In addition, to investigate the critical concentration and time exposure to $A \beta$, the formation time of the damage memory were estimated when the cells were incubated with different concentrations of $\mathrm{A} \beta$. The results suggested that the formation time of the damage memory is $A \beta$ concentration dependent whose curve fits $E_{\max }$ model (Fig. 7C). With $\mathrm{A} \beta$ concentration getting higher, the damage memory forms earlier.

After the baseline time of endothelial damage memory formation is estimated, the effect of sirt-1 activator or $\mathrm{NAD}^{+}$supplement on delaying endothelial damage memory formation is investigated. The above simulation shows that the formation of 
endothelial damage memory may be delayed to $6 \mathrm{~h}$ or $8 \mathrm{~h}$ after $A \beta_{1-42}$ incubation by SRT 2104 or $\mathrm{NAD}^{+}$supplement respectively. Therefore, the cell experimets were desinged according to the simulation (Fig. 11B-C). The results of SRT2104 treatment are shown in Fig. 8A. The results suggested that the cell vitality in 4h SRT2104 group (including low dose and high dose) is significantly higher ( $<<0.05, \mathrm{t}=5.17$, $\mathrm{t}$-test) than that in 6h SRT2014 (including low dose and high dose) group and damage memory group meanwhile there is no significant difference $(\mathrm{p}>0.05, \mathrm{t}=-1.05, \mathrm{t}$-test $)$ between 6h SRT2104 (including low dose and high dose) group and damage memory group. Compared with the damage memory group, the levels of ROS and $\mathrm{p} 66^{\mathrm{SHC}}$ decreased significantly $\left(p_{R O S}<0.01, \quad t_{R O S}=-11.89 ; p_{p 66}<0.05, \quad t_{p 66}=-33.37\right.$, t-test $)$ meanwhile the levels of Mn-SOD, MMP, sirt-1 activity and $\mathrm{NAD}^{+}$increased significantly $\left(p_{S O D}<0.01, t_{S O D}=10.41 ; \mathrm{p}_{\mathrm{MMP}}<0.05, \mathrm{t}_{\mathrm{MMP}}=3.78 \mathrm{p}_{\mathrm{NAD}^{+}}<\right.$ $0.05, \mathrm{t}_{\mathrm{NAD}^{+}}=3.46 ; p_{\text {sirt }}<0.01, t_{\text {sirt }}=5.59$, t-test $)$ in SRT2104 treated cells. Therefore, treating with SRT2104 may delay the endothelial damage memory formation to $6 \mathrm{~h}$ after $A \beta_{1-42}$ incubation.

The results of $\mathrm{NAD}^{+}$supplement treatment are shown in Fig. 8B. The cell vitality in $6 \mathrm{~h} \mathrm{NAD}^{+}$group (including low dose and high dose) is significantly higher $(\mathrm{p}<0.05$, $\mathrm{t}=9.11$, $\mathrm{t}$-test) than that in $8 \mathrm{~h} \mathrm{NAD}^{+}$(including low dose and high dose) group and damage memory group meanwhile there is no significant $(\mathrm{p}>0.05, \mathrm{t}=2.11$, $\mathrm{t}$-test $)$ difference between $8 \mathrm{~h} \mathrm{NAD}^{+}$(including low dose and high dose) group and damage memory group. Compared with the damage memory group, the levels of ROS and p66 ${ }^{\mathrm{SHC}}$ decreased significantly $\left(p_{R O S}<0.01, t_{R O S}=-11.89 ; p_{p 66}<0.05\right.$, $t_{p 66}=-8.94$, t-test) meanwhile the levels of sirt-1 activity, Mn-SOD and MMP increased significantly $\left(p_{\text {sirt }}<0.01, t_{\text {sirt }}=4.70 ; p_{S O D}<0.05, t_{S O D}=2.68\right.$; $p_{p 66}<0.05, t_{p 66}=3.61, \mathrm{t}$-test) in $\mathrm{NAD}^{+}$treated cells. Therefore, treating with $\mathrm{NAD}^{+}$ may delay the endothelial damage memory formation to $8 \mathrm{~h}$ after $\mathrm{A} \beta_{1-42}$ incubation. Therefore, the experiments results suggested that compared with sirt-1 activator, $\mathrm{NAD}^{+}$supplement may exhibit better effects on delaying the formation of endothelial damage memory (Fig. 8C).

\section{Discussion}


Previous research has demonstrated that cerebrovascular endothelial cell damage is recognized as a contributor to the $\mathrm{AD}$ pathogenesis and $\mathrm{A} \beta$ may impair the cerebrovascular function $[10,20]$. But AD animal models researches show that the cerebrovascular function can not be improved by removing $A \beta[9,11,12]$. In this study, a new feature termed as cerebrovascular endothelial cell damage memory is revealed to explain this paradoxical previous results.

Our results suggested that sirt-1 may involve in the formation of cerebrovascular endothelial cell damage memory (Fig. 9). sirt-1 is a $\mathrm{NAD}^{+}$dependent protein deacetylase which occupies in cytoplasm and nucleus [21]. It may suppress gene transcription of the mitochondrial adaptor $\mathrm{p} 66^{\mathrm{SHC}}$ by deacetylating histone 3 binding to the $\mathrm{p} 66^{\mathrm{SHC}}$ promoter $[22,23]$. Whereas inhibition of sirt-1 increased acetylated histone $\mathrm{H} 3$ binding to the $\mathrm{p} 66^{\mathrm{SHC}}$ promoter and induce overexpression of $\mathrm{p} 66^{\mathrm{SHC}}$. The increased $\mathrm{p} 66^{\mathrm{SHC}}$ would open the mitochondrial permeability transition pore (PTP) which may result into the collapse of the mitochondrial membrane potential (MMP) [24]. When the PTP opens, the contact between the cytosolic and the mitochondrial pools of pyridine nucleotides may reduce $\mathrm{NAD}^{+}$via enzymatic reactions [25]. According to the above researches, a hypothesis for the mechanism of cerebrovascular endothelial damage memory is proposed: the sirt-1 level of cerebrovascular endothelial cell may be decreased by $A \beta$ exposure, then the decreased sirt- 1 could overexpress p6 $^{\mathrm{SCH}}$ which may cause MMP collapse inducing $\mathrm{NAD}^{+}$level reduction; meanwhile $\mathrm{NAD}^{+}$is a vital coenzyme of sirt- 1 , low level $\mathrm{NAD}^{+}$may exacerbate sirt-1 deactivation then further reduce MMP which may form a vicious circle. sirt-1 downregulation may be related to the ROS production induced by $A \beta$. Our results suggested that the damage memroy may induce ROS accumulation which is consistent with previous researches. Previous clinical research has demonstrated that the significant correlation between sirt- 1 and $A \beta$ levels in the brain as seen in human patients and $A \beta$ may suppress the expression of sirt-1 [26]. Therefore, $A \beta$ induced ROS production may cause the depletion of sirt-1 expression [27, 28].

Furthermore, the dynamic process of cerebrovascular endothelial cell damage memory formation is investigated by the mechanism based kinetic progression model. 
According to our model, the progression of cerebrovascular endothelial cell damage memory might be divided into two phases. The first phase termed as the formation phase is defined that the cell vitality can be recovered by removing $A \beta_{1-42}$. The second phase termed as the maintenance phase is defined that the cell vitality can not be recovered by removing $A \beta_{1-42}$. The roles of sirt- 1 and $\mathrm{NAD}^{+}$are different in different phases. The sirt-1 is an initiator in the formation phase. The decreased sirt-1 level may collapse the mitochondrial membrane potential which may inhibit the production of $\mathrm{NAD}^{+}$. As $\mathrm{NAD}^{+}$is exhausted, even if sirt-1 level recovers, it may not be fully function as the histone deacetylase for lacking crucial cofactor $\mathrm{NAD}^{+}$. In other words, when the maintenance phase is reached, lacking $\mathrm{NAD}^{+}$may be the important factor to maintain the endothelial damage vicious circle. In summary, decreased sirt-1 level is an initiator to activate endothelial damage vicious circle. When the vicious circle formed, it is maitained by low level $\mathrm{NAD}^{+}$and the variation of sirt-1 level only has limited impact on the damage vicious circle. Our experiments demonstrate that the vicious circle may induce mitochondria dysfunction and ROS accumulation. sirt-1, p66 $6^{\mathrm{SHC}}$ and Mn-SOD is affected by triggered vicious. In this study, our results suggested that $A \beta$ may suppress the expression of sirt- 1 which may cause the overexpression of $\mathrm{p} 66^{\mathrm{SHC}}$. Increased $\mathrm{p} 66^{\mathrm{SHC}}$ may open the mitochondrial permeability transition pore (PTP) which may result in the collapse of the mitochondrial membrane potential (MMP). When the PTP opens, the contact between the cytosolic and the mitochondrial pools of pyridine nucleotides may reduce $\mathrm{NAD}^{+}$ via enzymatic reactions. Meanwhile $\mathrm{NAD}^{+}$is a vital coenzyme of SIRT-1, low level $\mathrm{NAD}^{+}$may exacerbate sirt-1 deactivation then further reduce MMP which may form a vicious circle. Besides mitochondria dysfunction, the vicious circle may also induce ROS accumulation. The vicious circle may not only induce ROS production but also impair ROS elimination via suppress Mn-SOD expression. The above discussion is added to the revised manuscript.

The above kinetic process analysis may provide insight into the methods for the damage memory improvement which may contribute to reducing neuronal damage according to previous clinical research [29]. Our reseach suggested that both sirt-1 
activator and $\mathrm{NAD}^{+}$supplement may exihibit endothelial protection effects. Previous researches have demonstrated the roles of sirt- 1 in AD pathology. The loss of sirt-1 is closely associated with the accumulation of amyloid-beta and tau in the cerebral cortex of $\mathrm{AD}$ patients [18]. Researches in cell culature and genetic mouse models have identified the potential protective role of sirt-1 activators against $\mathrm{AD}[30,31]$. The sirt-1 activator SRT2104, similar to other sirt-1 activators, increased mitochondrial content and suppressed the inflammation pathways [32]. It also exhibits endothelial protective effects which is observed in this study [32]. Besides sirt-1 activators, $\mathrm{NAD}^{+}$boosters or supplement may have potential endothelial protective effects. Clinical research shown that stimulating $\mathrm{NAD}^{+}$metabolism in healthy middle-aged and older adults may reduce blood pressure and arterial stiffness [33]. However, the roles of the above treatments are still different in improving cerebrovascular endothelial cell damage memory. Compared with sirt-1 activator SRT2104, NAD ${ }^{+}$supplement may have more potent effects on delaying the formation of cerebrovascular endothelial cell damage memory. This result may be due to the different roles of sirt-1 and $\mathrm{NAD}^{+}$in the cerebrovascular endothelial cell damage memory dynamic process. sirt-1 may mainly plays a role in initializing the cerebrovascular endothelial cell damage vicious circle. Once the vicious circle formed, the variation of sirt-1 may have very limited impact on the vicious circle due to lacking the vital cofactor $\mathrm{NAD}^{+}$. Therefore, $\mathrm{NAD}^{+}$supplement or booster may be a potential method for improving the cerebrovascular endothelial cell damage memory. Furthermore, although our cell damage kinetics model is developed based the cell model produced by $A \beta_{1-42}$, previous research has suggested that the cytotoxicity of $A \beta_{1-40}$ and $A \beta_{1-42}$ are similar [34]. Therefore, the structure of the proposed model can be applied for $A \beta_{1-40}$ and the parameters of the proposed model may need to be further validated for $A \beta_{1-40}$.

\section{Conclusion}

In this study, the kinetic progression of cerebrovascular endothelial cell damage memory vicious circle is demonstrated. sirt-1 is an initiator to activate the above vicious circle. Once the vicious circle formed, it is maitained by low level $\mathrm{NAD}^{+}$ 
which suggested that $\mathrm{NAD}^{+}$supplement may be a potential method for improving the cerebrovascular endothelial cell damage memory. The present study provides a new insight into cerebrovascular endothelial damage in AD progression.

\section{Method}

\section{Research framework}

This study contains four steps (Fig. 10). Firstly, cell experiments are performed to investigate that whether the damage memory exists in endothelial cells and obtain the data for the kinetics process of cerebrovascular endothelial cells damage. Secondly, a mathematical model is developed to describe the above kinetics process. Thirdly, simulations based on the above model are performed to investigate the kinetic characters of the damage process and improvement method of cerebrovascular endothelial cells damage. Fourthly, the improvement method proposed by the above simulations are validated by cell experiments.

\section{Cell culture}

hCMEC/D3 cells were cultured in complete RPMI 1640 and seeded on glass coverslips in 12-well plates for ELISA and Western blot, 24-well plates for HPLC and MMP assays, or 96-well plates for cell vitality and ROS assays. All cell lines were maintained at $37^{\circ} \mathrm{C}$ and $5 \% \mathrm{CO}_{2}$. Cell lines were validated by short tandem repeat (STR) profiling.

\section{Cell treatment}

$\mathrm{A} \beta$ peptide is used to prepare $\mathrm{AD}$ cerebrovascular endothelial cell dysfunction model. The stock solution of $\mathrm{A} \beta$ peptide $(100 \mu \mathrm{M})$ is prepared by dissolving $1 \mathrm{mg}$ freeze-dried $\mathrm{A} \beta$ peptide powder in $2208 \mu \mathrm{L}$ PBS and $45 \mu \mathrm{L}$ DMSO. The stock solution is diluted to $2.5 \mu \mathrm{M}$ with complete RPMI 1640 solution for in vitro model preparation. To investigate that whether the cerebrovascular endothelial cell dysfunction memory exists in endothelial cells, the hCMEC/D3 cells are divided into three groups (Fig. 10A). For the first group (control group), the hCMEC/D3 cells were cultured in complete RPMI 1640. For the second group (the A $\beta$ group), the hCMEC/D3 cells are incubated with complete RPMI 1640 containing $2.5 \mu \mathrm{M}$ A $\beta$ peptide for $24 \mathrm{~h}$. For the third group (the damage memory group), the hCMEC/D3 
372 cells are incubated with $2.5 \mu \mathrm{M} A \beta$ peptide for $12 \mathrm{~h}$ and then withdraw $\mathrm{A} \beta$ for anther

$37312 \mathrm{~h}$ incubation. For all three groups, the cell samples are collected at $0 \mathrm{~h}, 2 \mathrm{~h}, 4 \mathrm{~h}, 6 \mathrm{~h}$, $3748 \mathrm{~h}, 10 \mathrm{~h}, 12 \mathrm{~h}, 14 \mathrm{~h}, 16 \mathrm{~h}, 18 \mathrm{~h}, 20 \mathrm{~h}, 22 \mathrm{~h}, 24 \mathrm{~h}$ for sirt-1, p66 ${ }^{\mathrm{SHC}}, \mathrm{NAD}^{+}$, ROS (Reactive

375 Oxygen Species), MMP and cell vitality measurement. For mechanistic experiments, 376 the cells in the damage memory group are treated with EX527 (a selective sirt-1 377 inhibitor), SRT2104 (a selective sirt-1 activator) and $\operatorname{NAD}^{+}[35,36]$.

\section{$378 \quad$ ELISA kit}

379 The expression of sirt-1 is measured by a commercial ELISA kit obtained from 380 abcam.

\section{Immunoblot}

The cells were lysed in RIPA buffer and quantified using a BCA assay. Equal amounts of total protein were separated by SDS-PAGE followed by electrophoretic transfer to polyvinylidene fluoride (PVDF) membranes (Millipore). After blocking membranes for $1 \mathrm{~h}$ with $5 \%$ skim milk powder in PBST, p66 ${ }^{\mathrm{SHC}}$ anti-body, amyloid beta anti-body or Mn-SOD anti-body were immunodetected by incubating for $16 \mathrm{~h}$ in primary antibody in blocking buffers. Membranes were washed extensively with PBST or TBST, and incubated with anti-rabbit secondary antibody in blocking buffer. After 1h, membranes were washed as above and developed using enhanced chemiluminescence. Densitometric images were captured with ImageJ and band intensity normalized to the control group.

\section{Cell vitality assay}

To evaluate the vitality of cells, the growth medium was disposed. Then wash the cells with PBS twice. $150 \mu \mathrm{L} 0.5 \mathrm{mg} / \mathrm{mL}$ MTT solution was added to each well of 96 well plates. After incubation for $90 \mathrm{~min}$ at $37^{\circ} \mathrm{C}$ with MTT, the supernatant in each well was removed. The precipitated formazan was solubilized with DMSO and quantified spectrophotometrically at 550nm.

\section{MMP assay}

Following an incubation with the $\mathrm{JC}-1$ at $37{ }^{\circ} \mathrm{C} / 45 \mathrm{~min}$, the culture medium was removed and plates were washed with PBS. Finally, fluorescence was measured in a Perkin Elmer LS-50B fluorescence microplate reader set at $525 \mathrm{~nm}$ (excitation) and 
$590 \mathrm{~nm}$ (emission).

\section{ROS measurement}

Following an incubation with the DCFH-DA $(10 \mu \mathrm{mol} / \mathrm{L})$ at $37^{\circ} \mathrm{C} / 20 \mathrm{~min}$, the culture medium was removed and plates were washed with PBS. Finally, fluorescence was measured in a Perkin Elmer LS-50B fluorescence microplate reader set at $488 \mathrm{~nm}$ (excitation) and $525 \mathrm{~nm}$ (emission).

\section{$\mathrm{NAD}^{+}$sample preparation and HPLC condition}

The cells were lysed by freeze-thaw cycles. The cell extractive was centrifuged for $10 \mathrm{~min}$ at $15000 \mathrm{rpm}$ under $4^{\circ} \mathrm{C} .100 \mu \mathrm{L}$ of the supernatant was stored at $-70{ }^{\circ} \mathrm{C}$ until analysis.

The prepared samples are analyzed by a HPLC method according to the previous research with slight modifications [37]. The prepared samples were injected into an Agilent ZORBAX SB-Aq column $(5.0 \mu \mathrm{m}, 150 \mathrm{~mm} \times 2.0 \mathrm{~mm})$. The mobile phase consisted of water containing $25 \mathrm{~g} / \mathrm{L} \mathrm{Na}_{2} \mathrm{HPO}_{4} \bullet 12 \mathrm{H}_{2} \mathrm{O}$. The flow rate of the mobile phase was $1 \mathrm{~mL} \cdot \mathrm{min}-1$. The injection volume was $20 \mu \mathrm{L}$. The column oven was conditioned at $+40^{\circ} \mathrm{C}$ and UV detection is set to $210 \mathrm{~nm}$.

\section{Sirt-1 activity assay}

The sirt-1 activity is measured by a commercial kit as instructed by the manufacturer (obtained form Yanyu Biotech, Shanghai, China ). The Cell Lysis solution was incubated with $5 \mu \mathrm{L}$ of flsorescence substrate $(100 \mu \mathrm{mol} / \mathrm{L})$ and $\mathrm{NAD}^{+}$ $(100 \mu \mathrm{mol} / \mathrm{L})$ for $30 \mathrm{~min}$ at $37{ }^{\circ} \mathrm{C}$. The fluorescence was subsequently monitored for $30 \mathrm{~min}$ at $360 \mathrm{~nm}$ (excitation) and $460 \mathrm{~nm}$ (emission).

\section{Mechanism based kinetic progression model development}

In this study, the data for model development is collected in the above cell experiment. After the model is developed, simulations are performed for investigating the dynamic characters of cerebrovascular endothelial damage memory. The mechanism based kinetic progression model is described in the system which is composed of five linked turn over equations: 


$$
\frac{d c_{\text {SIRT1 }}}{d t}=k_{\text {in }}^{\text {SIRT1 }} E_{A \beta}-k_{\text {out }}^{\text {SIRT } 1} c_{S I R T 1}
$$

$$
\frac{d c_{p 66^{S H C}}}{d t}=k_{\text {in }}^{p 66^{S H C}}\left(1-k_{p 66^{S H C}}^{S I R T 1} c_{S I R T 1}-k_{p 66^{S H C}}^{N A D^{+}} c_{N A D^{+}}\right)-k_{\text {out }}^{p 66^{S H C}} c_{p 66^{S H C}}
$$

$$
\frac{d c_{R O S}}{d t}=k_{i n}^{R O S} \frac{E_{\max }^{p 66^{S H C}} c_{p 66^{S H C}}}{E C_{50}^{p 66^{S H C}}+c_{p 66^{S H C}}}-k_{\text {out }}^{R O S} c_{R O S}
$$

$$
\frac{d c_{N A D^{+}}}{d t}=k_{\text {in }}^{N A D^{+}} c_{M M P}-k_{\text {out }}^{N A D^{+}} c_{N A D^{+}}
$$

$$
\frac{d c_{M M P}}{d t}=k_{\text {in }}^{M M P}-k_{\text {out }}^{M M P}\left(c_{M M P}+\frac{E_{\max }^{R O S} c_{R O S}}{E C_{50}^{R O S}+c_{R O S}}\right)
$$

$$
\frac{d c_{M T T}}{d t}=k_{\text {in }}^{M T T}\left(1+\frac{E_{\max }^{M M P} c_{M M P}}{E C_{50}^{M M P}+c_{M M P}}\right)-k_{\text {out }}^{M T T} c_{M T T}
$$

The basal equation of sirt-1 level (Eq. [1]) is depicted by a zero-order production rate $\left(k_{\text {in }}^{S I R T 1}\right)$ and a first-order degradation rate $\left(k_{\text {out }}^{S I R T 1}\right)$. In this system, the expression of sirt-1 may be inhibited by $A \beta$ whose concentration is constant in the cell experiments. Therefore, inhibition of sirt-1 expression induced by $A \beta$ is assumed to constant which is described by parameter $E_{A \beta}$. When the cell is incubated in growth medium without $\mathrm{A} \beta$, the value of $E_{A \beta}$ is set to 1 . The basal equation of $\mathrm{p} 66^{\mathrm{SHC}}$ level (Eq. [2]) is depicted by a zero-order production rate $\left(k_{i n}^{p 66^{5 H C}}\right)$ and a first-order degradation rate $\left(k_{\text {out }}^{p 66^{\text {SHC }}}\right)$. sirt-1 may decrease p66 ${ }^{\mathrm{SHC}}$ expression. Additionally, $\mathrm{NAD}^{+}$is the cofactor of sirt- 1 which may also affect the expression of $\mathrm{p} 66^{\mathrm{SHC}}$. The effects of sirt-1 and $\mathrm{NAD}^{+}$on $\mathrm{p}^{\mathrm{SHC}}{ }^{\mathrm{SHC}}$ expression are assumed to be linear which are described by parameters $k_{p 66^{S H C}}^{S I R T 1}$ and $k_{p 66^{S H C}}^{N A D^{+}}$respectively. The basal equation of ROS level (Eq.

[2]) is depicted by a zeros-order production rate $\left(k_{i n}^{R O S}\right)$ and a first-order degradation rate $\left(k_{\text {out }}^{R O S}\right)$. The effect of $\mathrm{p} 66^{\mathrm{SHC}}$ on rising ROS level is described by $E_{\max }$ model containing two parameters $E_{\max }^{p 66^{5 H C}}$ and $E C_{50}^{p 66^{S H C}}$. The basal equation of $\mathrm{NAD}^{+}$level 
(Eq. [3]) is depicted by a zero-order production rate $\left(k_{i n}^{N A D^{+}}\right)$and a first-order degradation rate $\left(k_{\text {out }}^{N A D^{+}}\right)$. The basal equation of MMP level (Eq. [4]) is depicted by a zero-order production rate $\left(k_{\text {in }}^{M M P}\right)$ and a first-order degradation rate $\left(k_{\text {out }}^{M M P}\right)$. The MMP collapse induced by ROS is assumed to be described by a $E_{\max }$ model which contains two parameters $E_{\max }^{R O S}$ and $E C_{50}^{R O S}$. The basal equation of cell vitality (Eq. [5]) is depicted by a zero-order production rate $\left(k_{i n}^{M T T}\right)$ and a first-order degradation rate $\left(k_{\text {out }}^{M T T}\right)$. The cell vitality may be affect by MMP whose effect is assumed to be described by a $E_{\max }$ model including two parameters $E_{\max }^{M M P}$ and $E C_{50}^{M M P}$.

\section{Simulation}

The simulation can provide insight into three issues. Firstly, the simulation can help find the time of cerebrovascular endothelial damage memory formation. For this scenario, $\mathrm{A} \beta$ is withdrawn at different time points and levels of sirt- $1, \mathrm{p} 66^{\mathrm{SHC}}, \mathrm{NAD}^{+}$, MMP and cell vitality are estimated to find the time at which the cell vitality may recover after $A \beta$ is withdrawn. The formation of cerebrovascular endothelial damage memory is defined as that the cell vitality decreases more than $30 \%$ compared with control group and it can not recover after $A \beta$ is withdrawn. Secondly, the influence factors for cerebrovascular endothelial damage memory formation are investigated by simulations. In this scenario, the effects of levels of sirt- 1 and its cofactor $\mathrm{NAD}^{+}$on cerebrovascular endothelial damage memory formation are investigated. When sirt-1 level or $\mathrm{NAD}^{+}$level changes, the time for cerebrovascular endothelial damage memory formation is estimated. Thirdly, the methods for delaying the formation of endothelial damage memory are investigated by simulation. In this scenario, the endothelial improvement effect of sirt-1 activator and $\mathrm{NAD}^{+}$supplement are simulated. The improvement method proposed by simulation is validated in cell experiments.

\section{Simulation validation}

To validate the simulation based on the kinetic progression, three cell 
experiments are performed. The aim of the first cell experiment is to validate the baseline time of the formation of endothelial damage memory (Fig. 11A). Validation of the baseline time could help us to compare the different endothelial function improvement methods. In the first experiment, the hCMEC/D3 cells were divided into four groups. In the first group (control group), the cells were incubated with complete RPMI 1640 for $24 \mathrm{~h}$. In the second group ( $2 \mathrm{~h}$ memory group), the cells were incubated with culture medium containing $A \beta_{1-42}$ for $2 \mathrm{~h}$ and then withdraw $A \beta_{1-42}$ for another $22 \mathrm{~h}$ incubation. In the third group ( $4 \mathrm{~h}$ memory group), the cells were incubated with culture medium containing $A \beta_{1-42}$ for $4 \mathrm{~h}$ and then withdraw $A \beta_{1-42}$ for another $20 \mathrm{~h}$ incubation. In the fourth group ( $\mathrm{A} \beta$ group), the cells were incubated with culture medium containing $A \beta_{1-42}$ for $24 \mathrm{~h}$. All the cell samples are collected for cell vitality measurement after $24 \mathrm{~h}$ incubation.

The aim of the second experiment is to investigate the effects of sirt-1 activator SRT2104 on delaying the formation of endothelial damage memory (Fig. 11B). In this experiment, the cells were divided into seven groups. In the first group (control group), the cells were incubated with complete RPMI 1640 for $24 \mathrm{~h}$. In the second group ( $A \beta$ group), the cells were incubated with $A \beta$ for $24 \mathrm{~h}$. In the third group (damage memory group), the protocol is same as the $4 \mathrm{~h}$ memory group in the first experiment. In the fourth and fifth groups (4h high and low dose SRT2104 groups), the cells were incubated with culture medium containing $A \beta_{1-42}$ for $4 \mathrm{~h}$ and then withdraw $A \beta_{1-42}$ for another $20 \mathrm{~h}$ incubation meanwhile the cells were treated with $2 \mu \mathrm{mol} / \mathrm{L}$ and $1 \mu \mathrm{mol} / \mathrm{L}$ SRT2104 respectively during the entire incubation. In the sixth and seventh groups (6h high and low dose SRT2104 group), the cells were incubated with culture medium containing $A \beta_{1-42}$ for $6 \mathrm{~h}$ and then withdraw $\mathrm{A} \beta_{1-42}$ for another $18 \mathrm{~h}$ incubation meanwhile the cells were treated with $2 \mu \mathrm{mol} / \mathrm{L}$ and $1 \mu \mathrm{mol} / \mathrm{L}$ SRT2104 respectively during the entire incubation.

The aim of the third experiment is to investigate the effects of sirt- 1 activator on delaying the formation of endothelial damage memory (Fig. 11C). In this experiment, the cells were divided into seven groups. The protocols of the first group (control group) and second (A $\beta$ group) are same as those groups in the second experiment. In 
507 the third group (damage memory group), the cells were incubated with culture 508 medium containing $A \beta$ for $6 \mathrm{~h}$ and then withdraw $A \beta$ for another $18 \mathrm{~h}$ incubation. In 509 the fourth and fifth groups (6h high and low dose $\mathrm{NAD}^{+}$groups), the cells were 510 incubated with culture medium containing $A \beta_{1-42}$ for $6 \mathrm{~h}$ and then withdraw $511 \mathrm{~A} \beta_{1-42}$ for another $18 \mathrm{~h}$ incubation meanwhile the cells were treated with $5 \mathrm{mmol} / \mathrm{L}$ 512 and $1 \mathrm{mmol} / \mathrm{L} \mathrm{NAD}^{+}$respectively during the entire incubation. In the sixth and 513 seventh groups ( $8 \mathrm{~h}$ high and low dose $\mathrm{NAD}^{+}$groups), the cells were incubated with 514 culture medium containing $A \beta_{1-42}$ for $8 \mathrm{~h}$ and then withdraw $A \beta_{1-42}$ for another $51516 \mathrm{~h}$ incubation meanwhile the cells were treated with $5 \mathrm{mmol} / \mathrm{L}$ and $1 \mathrm{mmol} / \mathrm{L}$ $516 \mathrm{NAD}^{+}$respectively during the entire incubation. All the cell samples were collected 517 after $24 \mathrm{~h}$ incubation for $\mathrm{p} 66^{\mathrm{SHC}}, \mathrm{NAD}^{+}, \mathrm{MMP}$ and cell vitality.

518 Abbreviations

AD: Alzheimer Disease; A $\beta$ : Beta-amyloid peptide; FBS: Fetal bovine serum; hCMEC/D3: Human cortical microvascular endothelial cell line D3; SIRT1: sirtuin-1; MMP: mitochondrial membrane potential;

\section{Declarations section}

\section{Ethical approval and consent to participate:}

All experiments were approved by the Animal Ethics Committee of China Pharmaceutical University.

Consent for publication:

Not applicable

Availability of supporting data:

All data generated or analyzed during this study are included in this article.

\section{Competing interests:}

532 The authors declare that they have no competing interests.

\section{Fundings}

This study was supported by the Natural Science Foundation of China (NO. 81773806 and NO. 81903703), "Double First-Class" University project (NO. CPU2018GY19). 


\section{Author contributions:}

LHC, LXQ, and HH designed the experiments. ZYX, XS, ZH, and ZHM conducted the experiments. LHC developed the mathematical model and wrote this manuscript. All authors read and approved the final manuscript.

\section{Acknowledgements}

The authors appreciate Prof. Liu xiaodong from China Pharmaceutical University for providing hCMEC/D3 cell.

\section{Authors' information:}

Not applicable

\section{References}

1. Rózga $M$, Bittner $T$, Batrla $R$ and Karl J. Preanalytical sample handling recommendations for Alzheimer's disease plasma biomarkers. Alzheimer's \& Dementia: Diagnosis, Assessment \& Disease Monitoring. 2019; 11(1):291-300.

2. Hardy JA and Higgins GA. ALZHEIMERS-DISEASE - THE AMYLOID CASCADE HYPOTHESIS. Science (80- ). 1992; 256(5054):184-185.

3. Wong CW, Quaranta $V$ and Glenner GG. Neuritic plaques and cerebrovascular amyloid in Alzheimer disease are antigenically related. Proc Natl Acad Sci U S A. 1985; 82(24):8729-8732.

4. Goure WF, Krafft GA, Jerecic J and Hefti F. Targeting the proper amyloid-beta neuronal toxins: a path forward for Alzheimer's disease immunotherapeutics. Alzheimers Res Ther. 2014; 6(4):42-42.

5. van Dyck $\mathrm{CH}$. Anti-Amyloid- $\beta$ Monoclonal Antibodies for Alzheimer's Disease: Pitfalls and Promise. Biol Psychiatry. 2018; 83(4):311-319.

6. Doody RS, Thomas RG, Farlow M, Iwatsubo T, Vellas B, Joffe S, Kieburtz K, Raman R, Sun XY, Aisen PS, Siemers E, Liu-Seifert H, Mohs R, et al. Phase 3 Trials of Solanezumab for Mild-to-Moderate Alzheimer's Disease. New England Journal Of Medicine. 2014; 370(4):311-321.

7. Tarasoff-Conway JM, Carare RO, Osorio RS, Glodzik L, Butler T, Fieremans E, Axel L, Rusinek H, Nicholson C, Zlokovic BV, Frangione B, Blennow K, Menard J, et al. Clearance systems in the brain-implications for Alzheimer disease. Nature Reviews Neurology. 2015; 11(8):457-470.

8. Qi XM and Ma JF. The role of amyloid beta clearance in cerebral amyloid angiopathy: more potential therapeutic targets. Translational Neurodegeneration. 2017; 6(2017):22.

9. Burbach GJ, Vlachos A, Ghebremedhin E, Del Turco D, Coomaraswamy J, Staufenbiel M, Jucker M and Deller T. Vessel ultrastructure in APP23 transgenic mice after passive anti-A beta immunotherapy and subsequent intracerebral hemorrhage. Neurobiol Aging. 2007; 28(2):202-212.

10. Johnson KA, Gregas M, Becker JA, Kinnecom C, Salat DH, Moran EK, Smith EE, Rosand J, Rentz DM, Klunk WE, Mathis CA, Price JC, DeKosky ST, et al. Imaging of amyloid burden and distribution in cerebral amyloid angiopathy. Ann Neurol. 2007; 62(3):229-234.

11. Racke MM, Boone LI, Hepburn DL, Parsadainian M, Bryan MT, Ness DK, Piroozi KS, Jordan WH, Brown DD, Hoffman WP, Holtzman DM, Bales KR, Gitter BD, et al. Exacerbation of cerebral amyloid angiopathy-associated microhemorrhage in amyloid precursor proteintransgenic mice by immunotherapy is dependent on antibody recognition of deposited forms of amyloid beta. Journal of 
Neuroscience. 2005; 25(3):629-636.

12. Wilcock DM, Alamed J, Gottschall PE, Grimm J, Rosenthal A, Pons J, Ronan V, Symmonds K, Gordon MN and Morgan D. Deglycosylated anti-amyloid-beta antibodies eliminate cognitive deficits and reduce parenchymal amyloid with minimal vascular consequences in aged amyloid precursor protein transgenic mice. Journal Of Neuroscience. 2006; 26(20):5340-5346.

13. Berezin A. Metabolic memory phenomenon in diabetes mellitus: Achieving and perspectives. Diabetes \& Metabolic Syndrome: Clinical Research \& Reviews. 2016; 10(2, Supplement 1):S176-S183. 14. Duckworth W, Abraira C, Moritz T, Reda D, Emanuele N, Reaven PD, Zieve FJ, Marks J, Davis SN, Hayward R, Warren SR, Goldman S, McCarren M, et al. Glucose Control and Vascular Complications in Veterans with Type 2 Diabetes. New England Journal Of Medicine. 2009; 360(2):129-U162.

15. Liu X, Jiao B and Shen L. The Epigenetics of Alzheimer's Disease: Factors and Therapeutic Implications. Front Genet. 2018; 9(579):1.

16. Testa R, Bonfigli AR, Prattichizzo F, La Sala L, De Nigris V and Ceriello A. The "Metabolic Memory" Theory and the Early Treatment of Hyperglycemia in Prevention of Diabetic Complications. Nutrients. 2017; 9(5):437.

17. Mastroeni D, Grover A, Delvaux E, Whiteside C, Coleman PD and Rogers J. Epigenetic mechanisms in Alzheimer's disease. Neurobiol Aging. 2011; 32(7):1161-1180.

18. Julien C, Tremblay C, Emond V, Lebbadi M, Norman S, Bennett DA and Calon F. Sirtuin 1 Reduction Parallels the Accumulation of Tau in Alzheimer Disease. J Neuropathol Exp Neurol. 2009; 68(1):48-58.

19. Zhou BD, Margariti A, Zeng LF and Xu QB. Role of histone deacetylases in vascular cell homeostasis and arteriosclerosis. Cardiovasc Res. 2011; 90(3):413-420.

20. Chakraborty A, Kamermans A, van het Hof B, Castricum K, Aanhane E, van Horssen J, Thijssen VL, Scheltens P, Teunissen CE, Fontijn RD, van der Flier WM and de Vries HE. Angiopoietin like-4 as a novel vascular mediator in capillary cerebral amyloid angiopathy. Brain. 2018; 141(2018):3377-3388.

21. Hirschey MD. Old Enzymes, New Tricks: Sirtuins Are NAD(+)-Dependent De-acylases. Cell Metab. 2011; 14(6):718-719.

22. Paneni F, Volpe M, Luscher TF and Cosentino F. SIRT1, p66(Shc), and Set7/9 in Vascular Hyperglycemic Memory. Diabetes. 2013; 62(6):1800-1807.

23. Zhou S, Chen HZ, Wan YZ, Zhang QJ, Wei YS, Huang SA, Liu JJ, Lu YB, Zhang ZQ, Yang RF, Zhang R, Cai H, Liu DP, et al. Repression of P66Shc Expression by SIRT1 Contributes to the Prevention of Hyperglycemia-Induced Endothelial Dysfunction. Circ Res. 2011; 109(6):639-U125.

24. Su K, Bourdette D and Forte M. Mitochondrial dysfunction and neurodegeneration in multiple sclerosis. Front Physiol. 2013; 4(2013):169.

25. Dumas JF, Argaud L, Cottet-Rousselle C, Vial G, Gonzalez C, Detaille D, Leverve X and Fontaine E. Effect of Transient and Permanent Permeability Transition Pore Opening on NAD(P)H Localization in Intact Cells. Journal Of Biological Chemistry. 2009; 284(22):15117-15125.

26. Julien C, Tremblay C, Emond V, Lebbadi M, Salem Jr N, Bennett DA and Calon F. Sirtuin 1 reduction parallels the accumulation of tau in Alzheimer disease. Journal of Neuropathology \& Experimental Neurology. 2009; 68(1):48-58.

27. Pallàs M, Pizarro JG, Gutierrez-Cuesta J, Crespo-Biel N, Alvira D, Tajes M, Yeste-Velasco M, Folch J, Canudas AM, Sureda FX, Ferrer I and Camins A. Modulation of SIRT1 expression in different neurodegenerative models and human pathologies. Neuroscience. 2008; 154(4):1388-1397.

28. Varadarajan S, Yatin S, Aksenova $M$ and Butterfield DA. Review: Alzheimer's Amyloid 
622 29. Li NC, Lee A, Whitmer RA, Kivipelto M, Lawler E, Kazis LE and Wolozin B. Use of angiotensin receptor blockers and risk of dementia in a predominantly male population: prospective cohort analysis. Bmj-British Medical Journal. 2010; 340(2012):b5465. 30. Chen J, Zhou YG, Mueller-Steiner S, Chen LF, Kwon H, Yi SL, Mucke L and Li G. SIRT1 protects against microglia-dependent amyloid-beta toxicity through inhibiting NF-kappa B signaling. Journal Of Biological Chemistry. 2005; 280(48):40364-40374.

31. Donmez G and Guarente L. Aging and disease: connections to sirtuins. Aging Cell. 2010; $9(2): 285-290$.

630 32. Granchi $C$ and Minutolo F. Activators of Sirtuin-1 and their Involvement in Cardioprotection. Curr 631 Med Chem. 2018; 25(34):4432-4456.

632 33. Martens CR, Denman BA, Mazzo MR, Armstrong ML, Reisdorph N, McQueen MB, Chonchol M 633 and Seals DR. Chronic nicotinamide riboside supplementation is well-tolerated and elevates NAD(+) in 634 healthy middle-aged and older adults. Nat Commun. 2018; 9(2018):1286.

635 34. Tekirian TL, Yang AY, Glabe $C$ and Geddes JW. Toxicity of Pyroglutaminated Amyloid $\beta$-Peptides $6363(\mathrm{pE})-40$ and -42 Is Similar to That of A 1-40 and -42. J Neurochem. 1999; 73(4):1584-1589.

637 35. Peck B, Chen CY, Ho KK, Di Fruscia P, Myatt SS, Coombes RC, Fuchter MJ, Hsiao CD and Lam EWF. 638 SIRT Inhibitors Induce Cell Death and p53 Acetylation through Targeting Both SIRT1 and SIRT2. Mol 639 Cancer Ther. 2010; 9(4):844-855.

640 36. Venkatasubramanian S, Noh RM, Daga S, Langrish JP, Joshi NV, Mills NL, Hoffmann E, Jacobson 641 EW, Vlasuk GP, Waterhouse BR, Lang NN and Newby DE. Cardiovascular Effects of a Novel SIRT1 642 Activator, SRT2104, in Otherwise Healthy Cigarette Smokers. J Am Heart Assoc. 2013; 2(3):UNSP $643 \mathrm{e} 000042$.

644 37. Forrow NJ and Shabir GA. Development and Validation of a HPLC Method for NAD: Application to 645 Stability Studies in Buffered Solutions and Dry Test Strips. J Liq Chromatogr Relat Technol. 2009; 646 32(19):2805-2821. 
Table 1 mechanism based kinetic process model parameters and bootstrap validation.

\begin{tabular}{|c|c|c|c|c|c|}
\hline \multirow[t]{2}{*}{ Parameters } & \multirow[t]{2}{*}{ Estimate } & \multirow[t]{2}{*}{$\mathrm{CV}$} & \multicolumn{2}{|c|}{ CI } & \multirow[t]{2}{*}{ Bootstrap } \\
\hline & & & LL & UL & \\
\hline$k_{i n}^{S I R T 1}$ & 0.02 & $77.05 \%$ & $4.73 \mathrm{E}-03$ & 0.04 & 0.02 \\
\hline$E_{A \beta}$ & -0.63 & $77.05 \%$ & -1.12 & -0.15 & -0.63 \\
\hline$k_{\text {out }}^{\text {SIRT } 1}$ & 0.10 & $35.96 \%$ & 0.07 & 0.14 & 0.11 \\
\hline$k_{i n}^{p 66^{S H C}}$ & 0.06 & $65.20 \%$ & 0.02 & 0.11 & 0.06 \\
\hline$k_{p 66^{S H C}}^{S I R T 1}$ & 28.29 & $67.40 \%$ & 9.22 & 47.36 & 28.29 \\
\hline$k_{p 66^{S H C}}^{N A D^{+}}$ & 13.05 & $81.77 \%$ & 2.38 & 23.73 & 13.50 \\
\hline$k_{\text {out }}^{p 66^{\text {SHC }}}$ & 1.42 & $7.29 \%$ & 1.31 & 1.52 & 1.42 \\
\hline$k_{i n}^{R O S}$ & 1.11 & $0.22 \%$ & 1.10 & 1.11 & 1.11 \\
\hline$E_{\max }^{p 66^{S H C}}$ & 0.32 & $19.86 \%$ & 0.26 & 0.38 & 0.35 \\
\hline$E C_{50}^{p 66^{5 H C}}$ & 0.11 & $96.27 \%$ & 4.01E-03 & 0.21 & 0.11 \\
\hline$k_{\text {out }}^{p 66^{S H C}}$ & 1.11 & $0.22 \%$ & 1.10 & 1.11 & 1.11 \\
\hline$k_{i n}^{N A D^{+}}$ & 0.26 & $58.87 \%$ & 0.11 & 0.41 & 0.27 \\
\hline$k_{\text {out }}^{N A D^{+}}$ & 0.21 & $78.28 \%$ & 0.05 & 0.38 & 0.23 \\
\hline$k_{i n}^{M M P}$ & 0.86 & $88.70 \%$ & 0.05 & 1.58 & 0.71 \\
\hline$E_{\max }^{R O S}$ & 1.11 & $0.15 \%$ & 1.17 & 1.17 & 1.04 \\
\hline$E C_{50}^{R O S}$ & 0.03 & $0.11 \%$ & 0.03 & 0.03 & 0.03 \\
\hline$k_{\text {out }}^{M M P}$ & 1.17 & $92.09 \%$ & 0.03 & 2.18 & 1.02 \\
\hline$k_{i n}^{M T T}$ & 0.94 & $83.68 \%$ & 0.15 & 1.72 & 0.94 \\
\hline$E_{\max }^{M M P}$ & 0.26 & $15.85 \%$ & 0.21 & 0.30 & 0.26 \\
\hline$E C_{50}^{M M P}$ & 0.04 & $78.74 \%$ & 0.01 & 0.08 & 0.04 \\
\hline
\end{tabular}




\begin{tabular}{llllll}
\hline$k_{\text {out }}^{\text {MTT }}$ & 1.04 & $78.53 \%$ & 0.22 & 1.85 & 1.04 \\
\hline
\end{tabular}

649

650 
Figures:
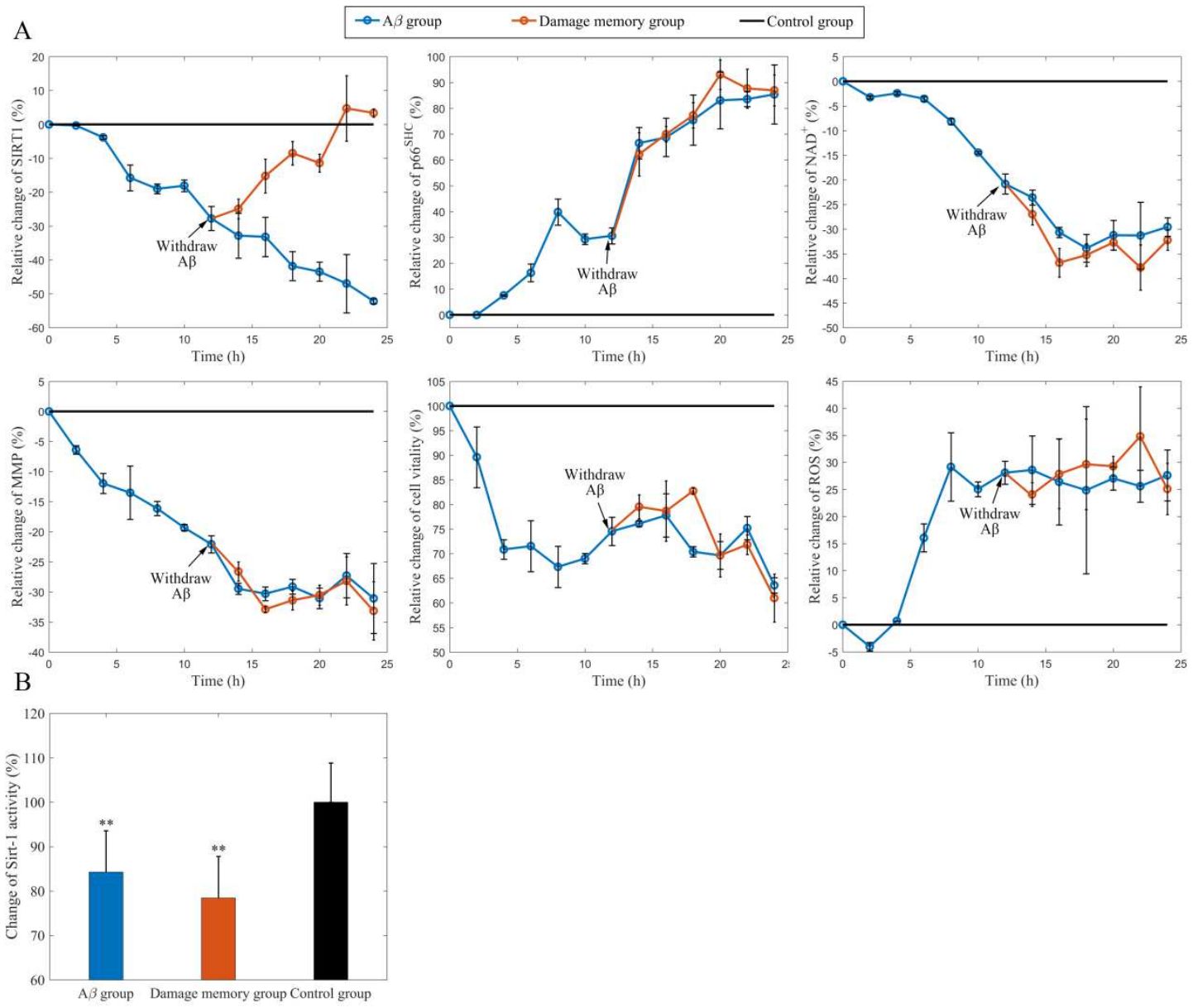

Fig. 1 A: the time course of relative change of sirt-1, p $66^{\mathrm{SHC}}, \mathrm{NAD}^{+}, \mathrm{ROS}, \mathrm{MMP}$, and cell vitality compared to the control group. The black line represent the control group level which is normalized to $100 \%$. The blue line represent $A \beta$ group level. The red line represent the damage memory group. $\mathrm{B}$ : the levels of sirt-1 activity in damage memory group, $A \beta$ group and control group. 
A

$\mathrm{C}$
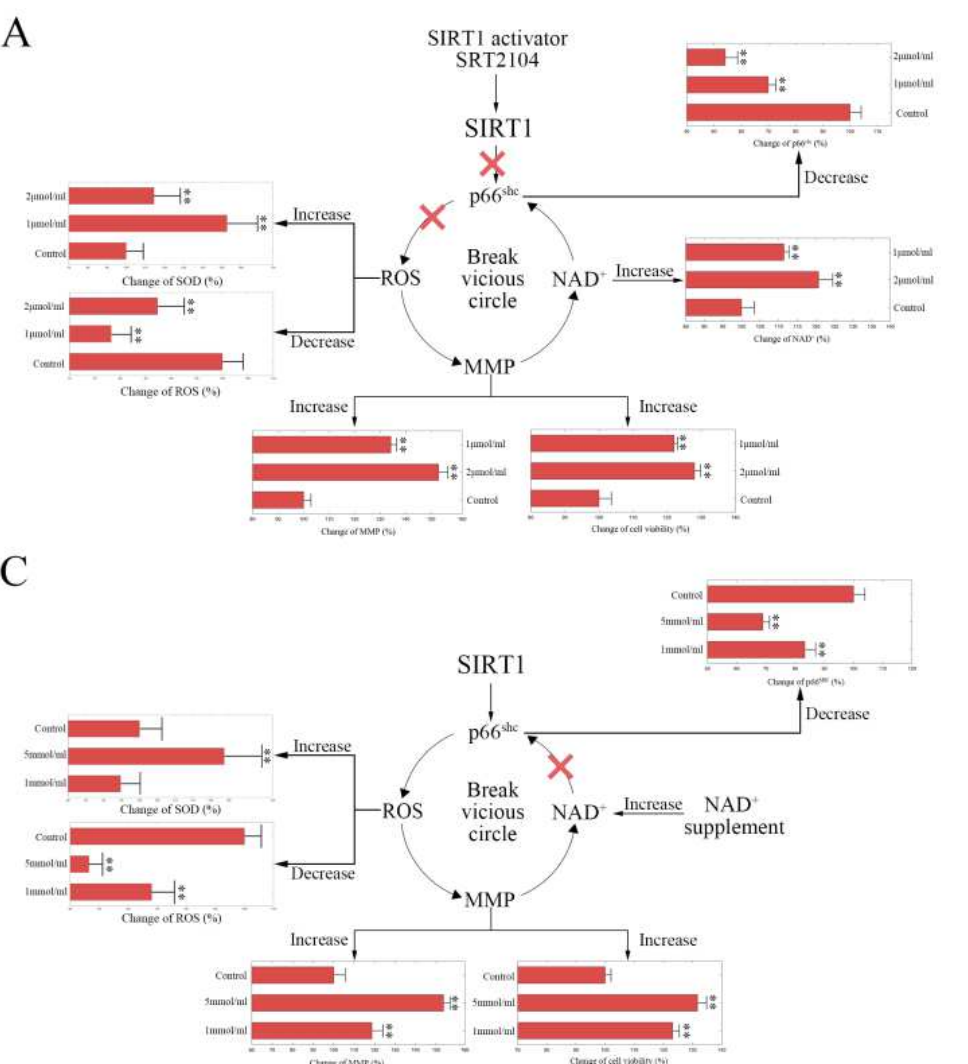

B

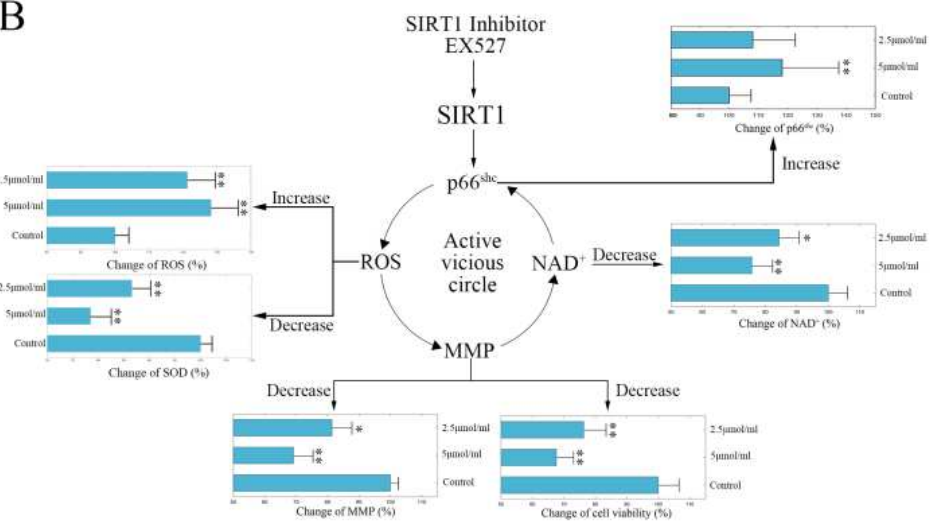

Fig. 2 A: the change of p6 $^{\mathrm{SHC}}$, NAD ${ }^{+}$, MMP, ROS, Mn-SOD and cell vitality in SRT2104 treated hCMEC/D3 cell. The control group data is normalized to $100 \%$. B: the change of $\mathrm{p}^{\mathrm{SHC}} \mathrm{NAD}^{+}, \mathrm{MMP}, \mathrm{ROS}, \mathrm{Mn}-\mathrm{SOD}$ and cell vitality in EX527 treated hCMEC/D3 cell. The control group data is normalized to $100 \%$. C: the change of p66 ${ }^{\mathrm{SHC}}$, MMP, ROS, Mn-SOD and cell vitality in $\mathrm{NAD}^{+}$supplement treated hCMEC/D3 cell. The control group data is normalized to $100 \%$. ** $\mathrm{p}<0.01 * \mathrm{p}<0.05$ 
A
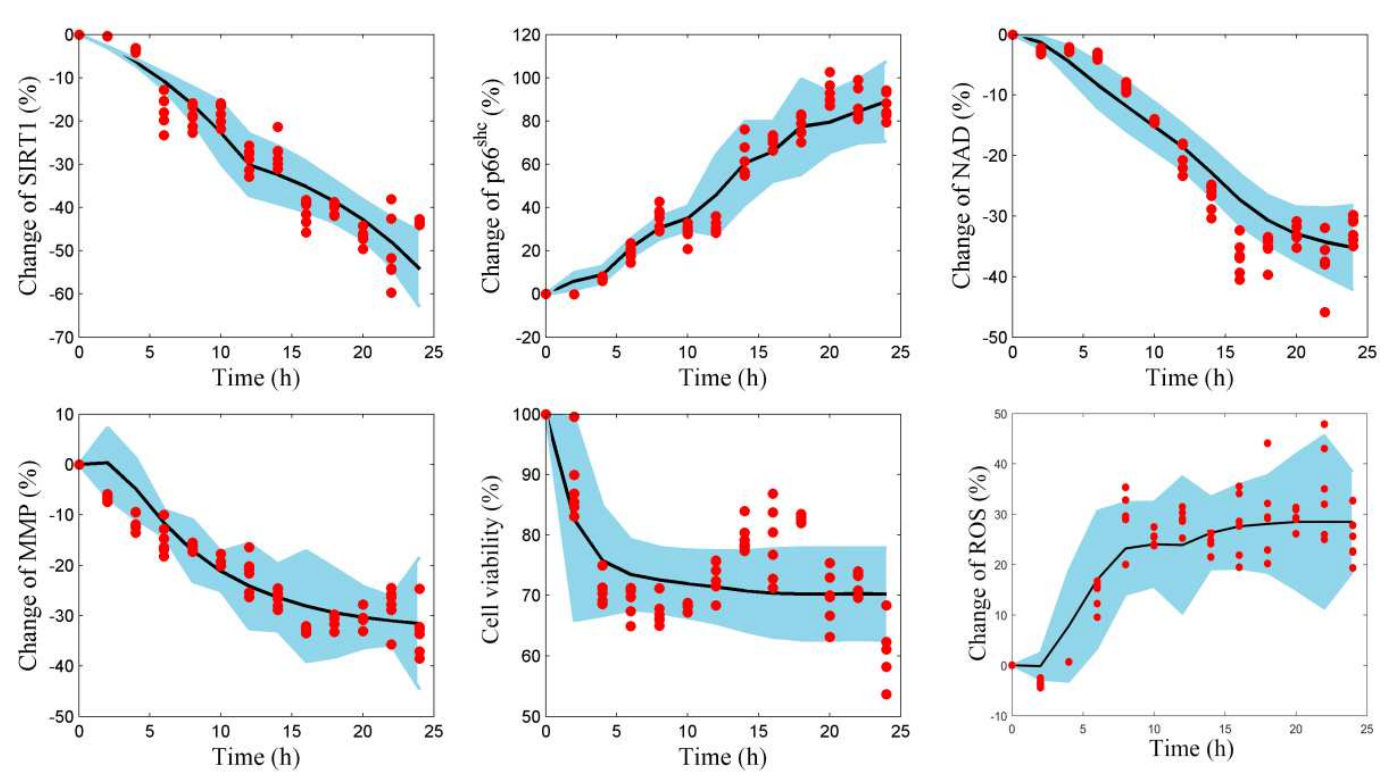

$\mathrm{B}$
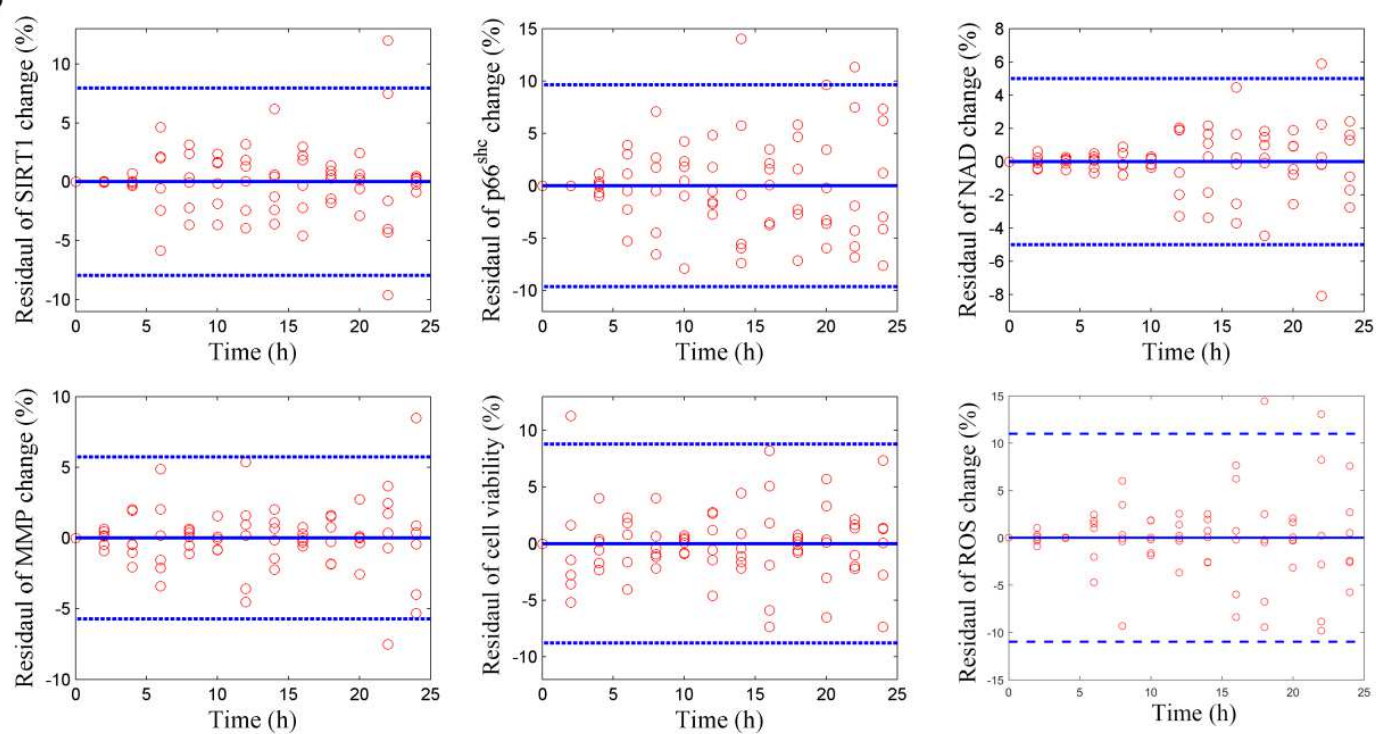

Fig. 3 A: visual predicted check (VPC) for sirt-1, p66 ${ }^{\mathrm{SHC}}$, ROS, NAD ${ }^{+}, \mathrm{MMP}$, and cell vitality. The shaded area represents the $95 \%$ confidence interval of the simulated median value. The line represents the median value of observed value. The red scatters represent observed values. B: scatter plots of predicted residuals vs. time for sirt-1, p $66^{\mathrm{SHC}}, \mathrm{ROS}, \mathrm{NAD}^{+}, \mathrm{MMP}$, and cell vitality. 

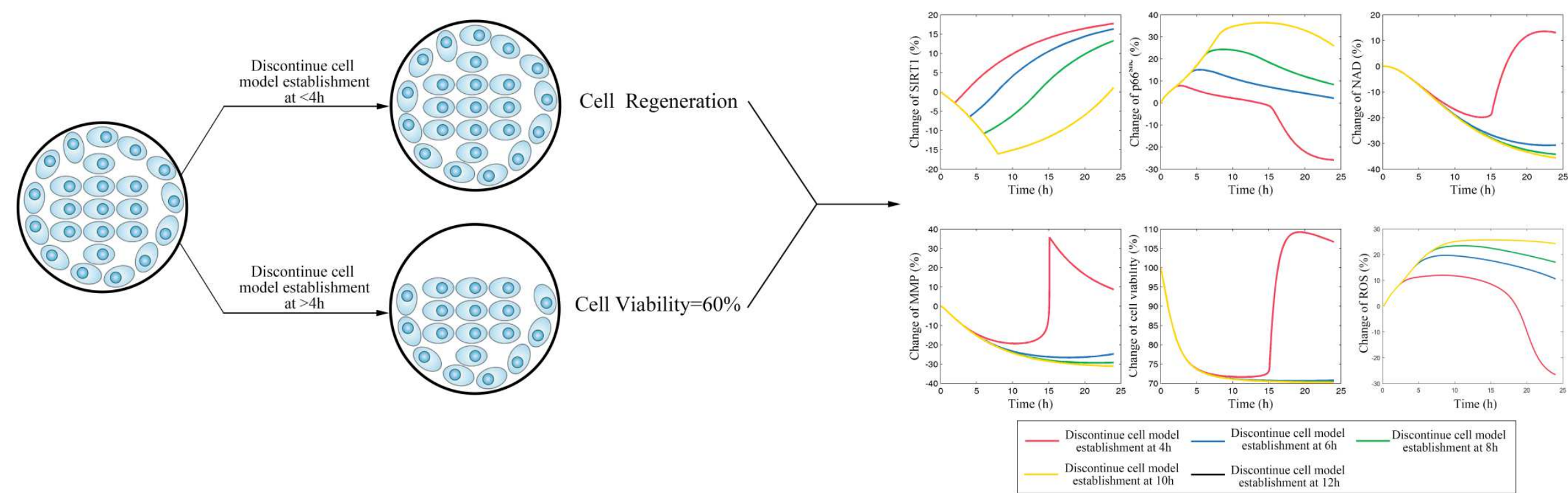

Fig. 4 the simulation results for scenario I which investigate the time of cerebrovascular endothelial cell damage memory formation. 

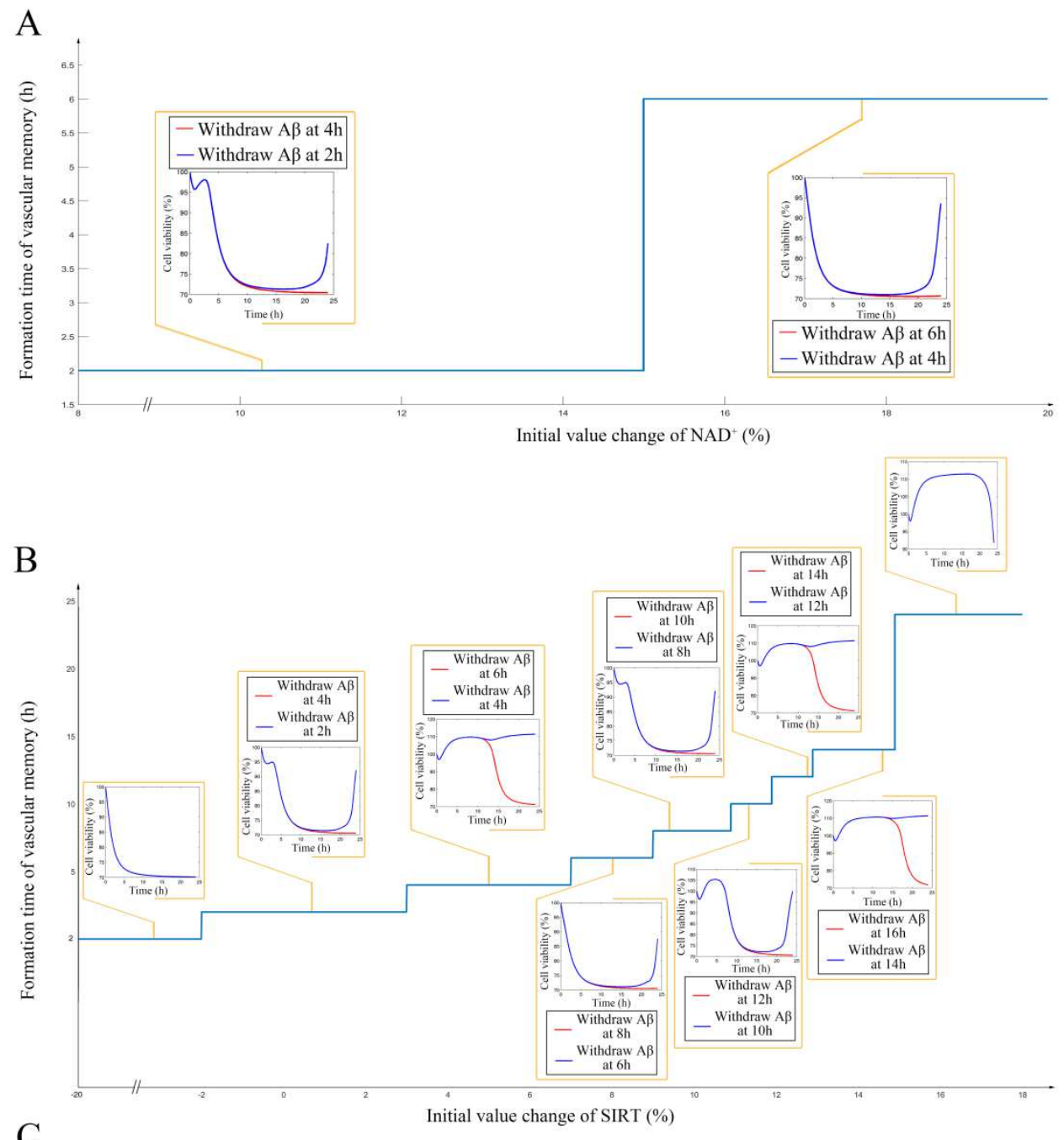

$\mathrm{C}$

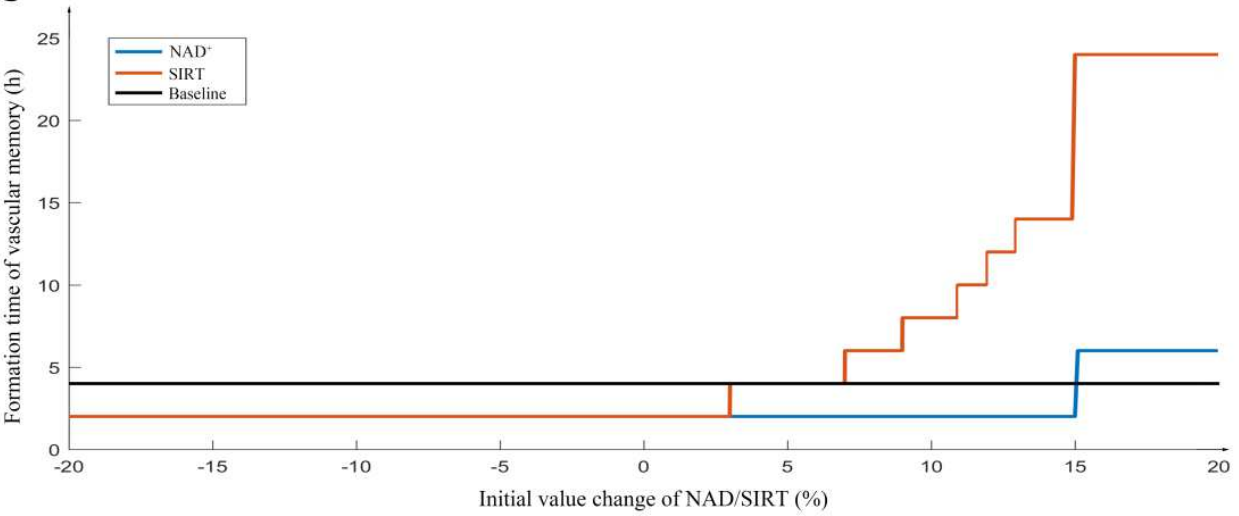

Fig. 5 A: the impact of different levels of $\mathrm{NAD}^{+}$on the cerebrovascular endothelial cell damage memory formation time. B: the impact of different levels of sirt-1 on the cerebrovascular endothelial cell damage memory formation time. C: the summary plot of the impact of different levels of sirt- 1 and $\mathrm{NAD}^{+}$on the cerebrovascular endothelial cell damage memory formation time. 


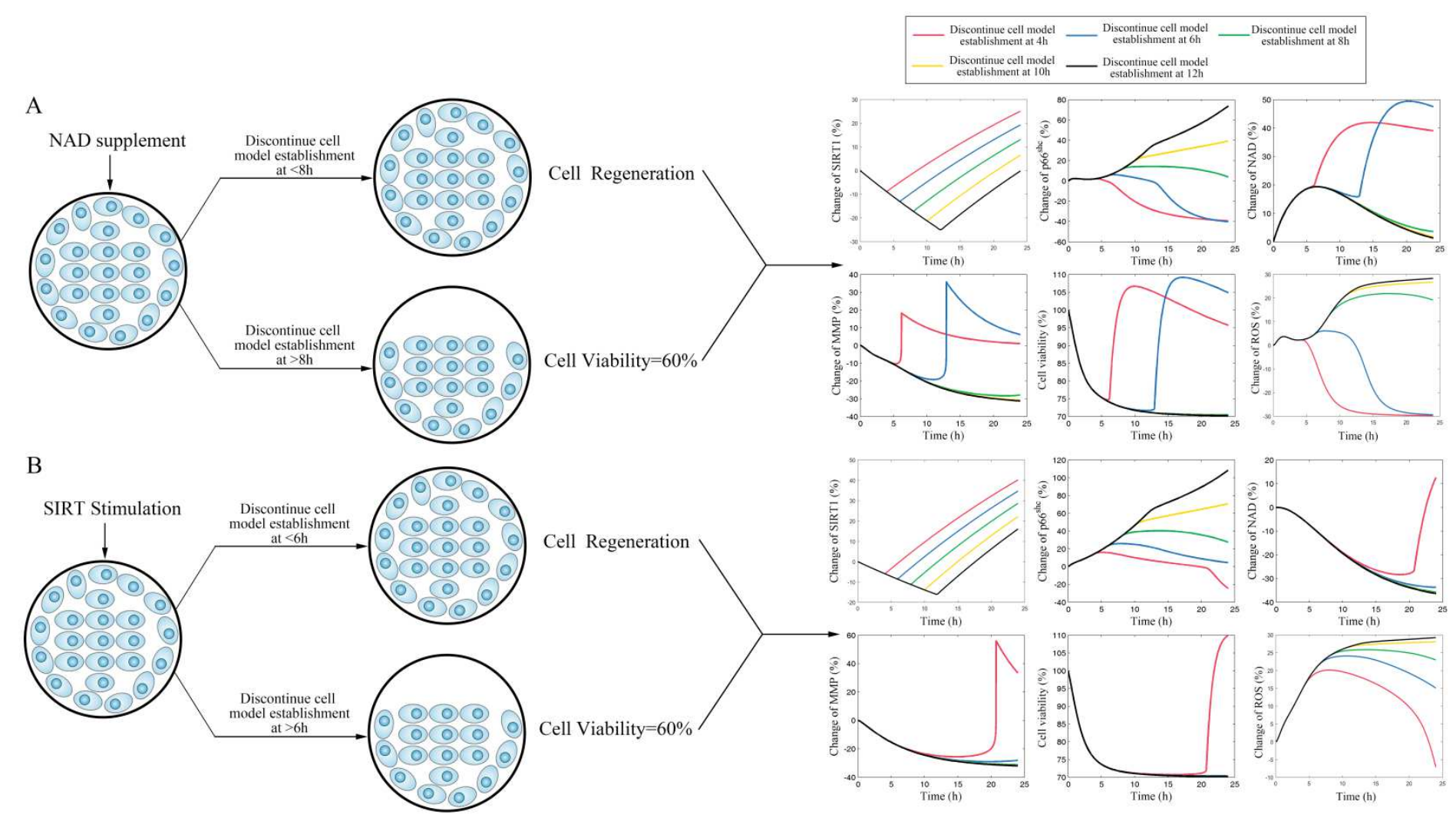

Fig. $6 \mathrm{~A}$ : the simulation for change of sirt-1, p66 ${ }^{\mathrm{SHC}}$, ROS, $\mathrm{NAD}^{+}, \mathrm{MMP}$, and cell vitality in $\mathrm{NAD}^{+}$supplement treated cells. B: the simulation for change of sirt-1, p $66^{\mathrm{SHC}}, \mathrm{ROS}, \mathrm{NAD}^{+}, \mathrm{MMP}$, and cell vitality in sirt-1 activator treated cells. 


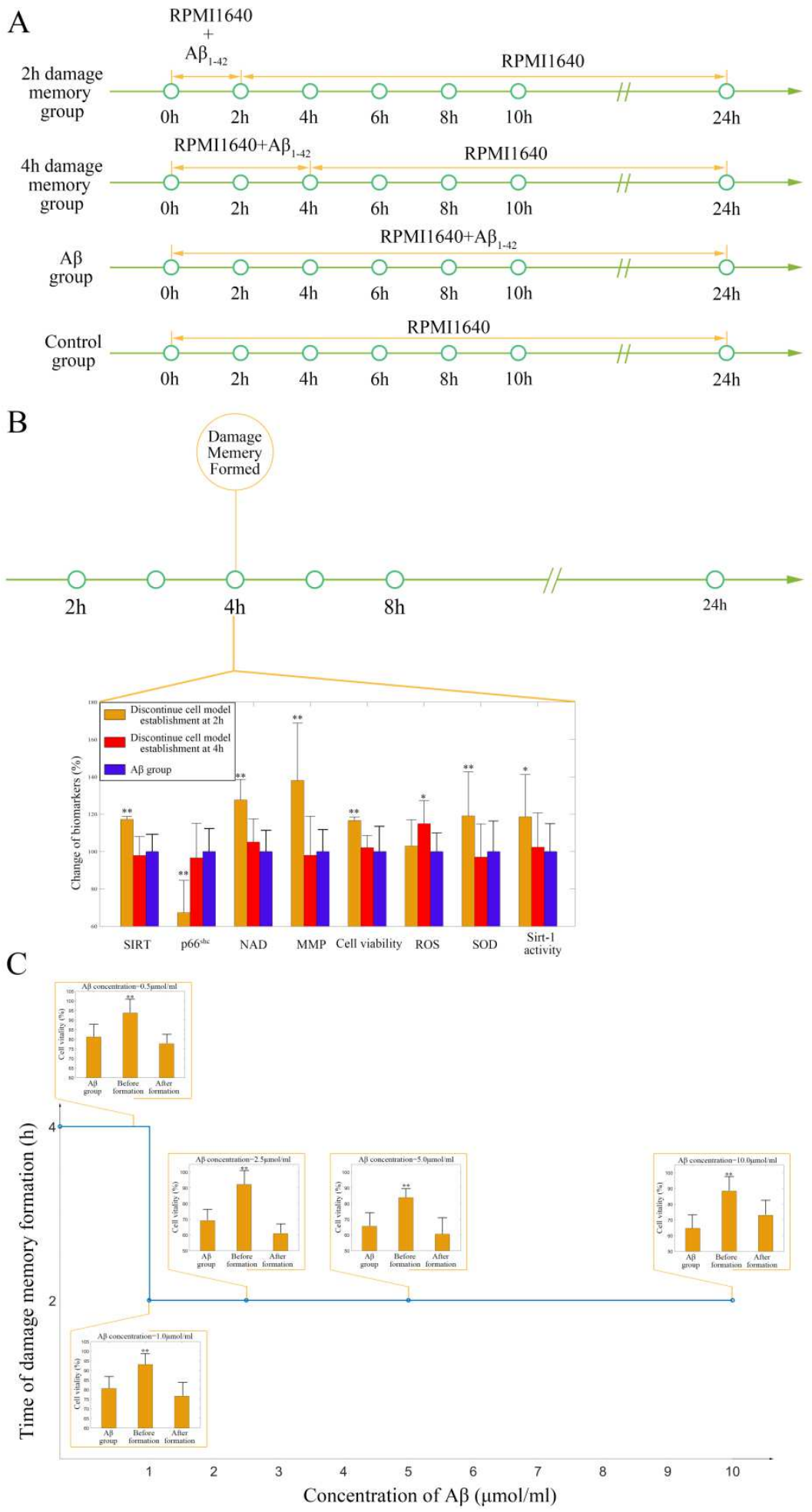

Fig. 7 A: experimental protocol for determining time of cerebrovascular endothelial cell damage memory formation. B: the experimental validation of cerebrovascular endothelial cell damage memory formation time. $C$ : the damage memory formation time with different concentration of $A \beta$ incubation. 
A
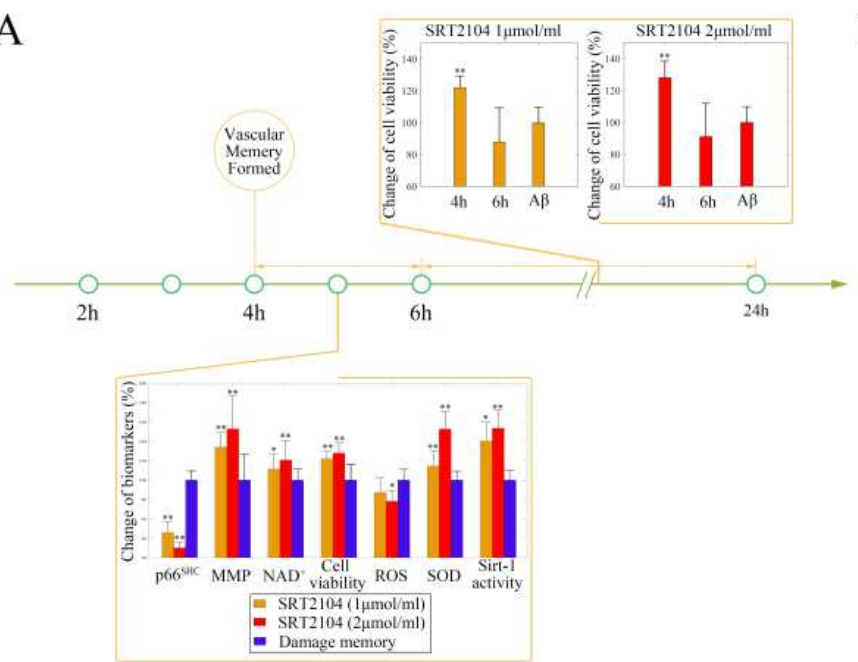

$\mathrm{C}$

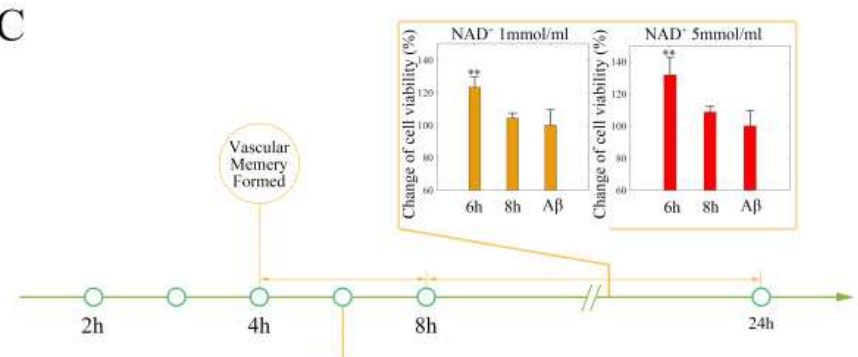

$\mathrm{E}$
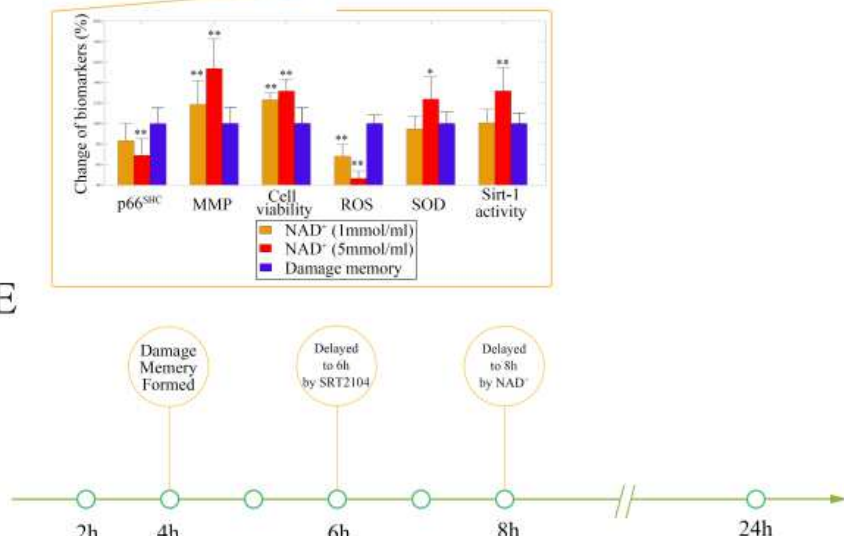

B
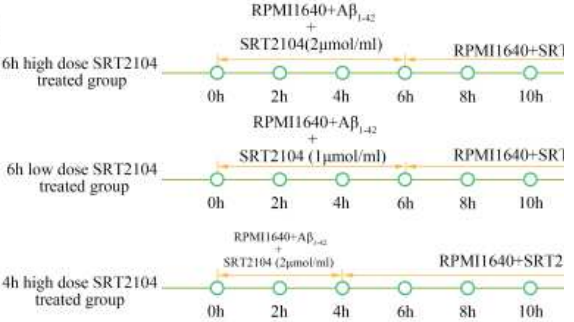

RPMIItato+A $A \beta_{100}$
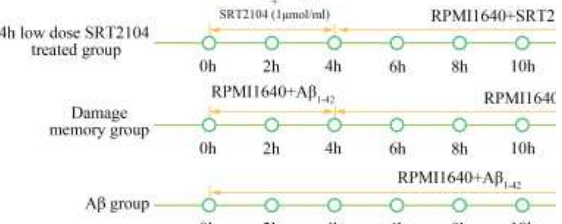

RPMU640

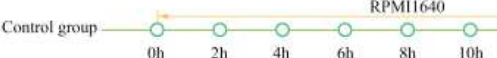

$\mathrm{D}$
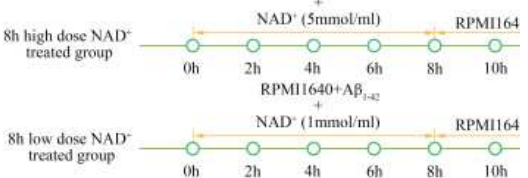

RPMI1640+A

$\mathrm{NAD}^{-}(5 \mathrm{mmol} / \mathrm{ml}) \quad \mathrm{RPM} I 640+\mathrm{NA}$

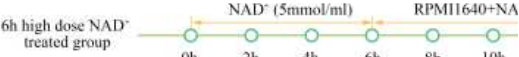

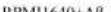

$\mathrm{NAD}^{*}$ (Immoliml) RPMII640+NA
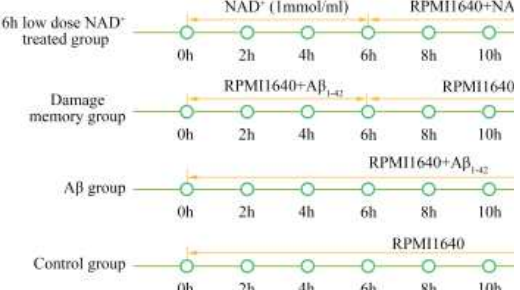

Fig. 8 A: the effect of SRT2104 on delaying the formation of cerebrovascular endothelial cell damage memory formation. B: experimental protocol for evaluating the effect of SRT2104 on delaying the formation of cerebrovascular endothelial cell damage memory. $\mathrm{C}$ : the effect of $\mathrm{NAD}^{+}$ supplement on delaying the formation of cerebrovascular endothelial cell damage memory formation. D: experimental protocol for evaluating the effect of $\mathrm{NAD}^{+}$supplement on delaying the formation of cerebrovascular endothelial cell damage memory. E: summary of the effect of SRT2104 and $\mathrm{NAD}^{+}$supplement on delaying the formation of cerebrovascular endothelial cell damage memory formation. 


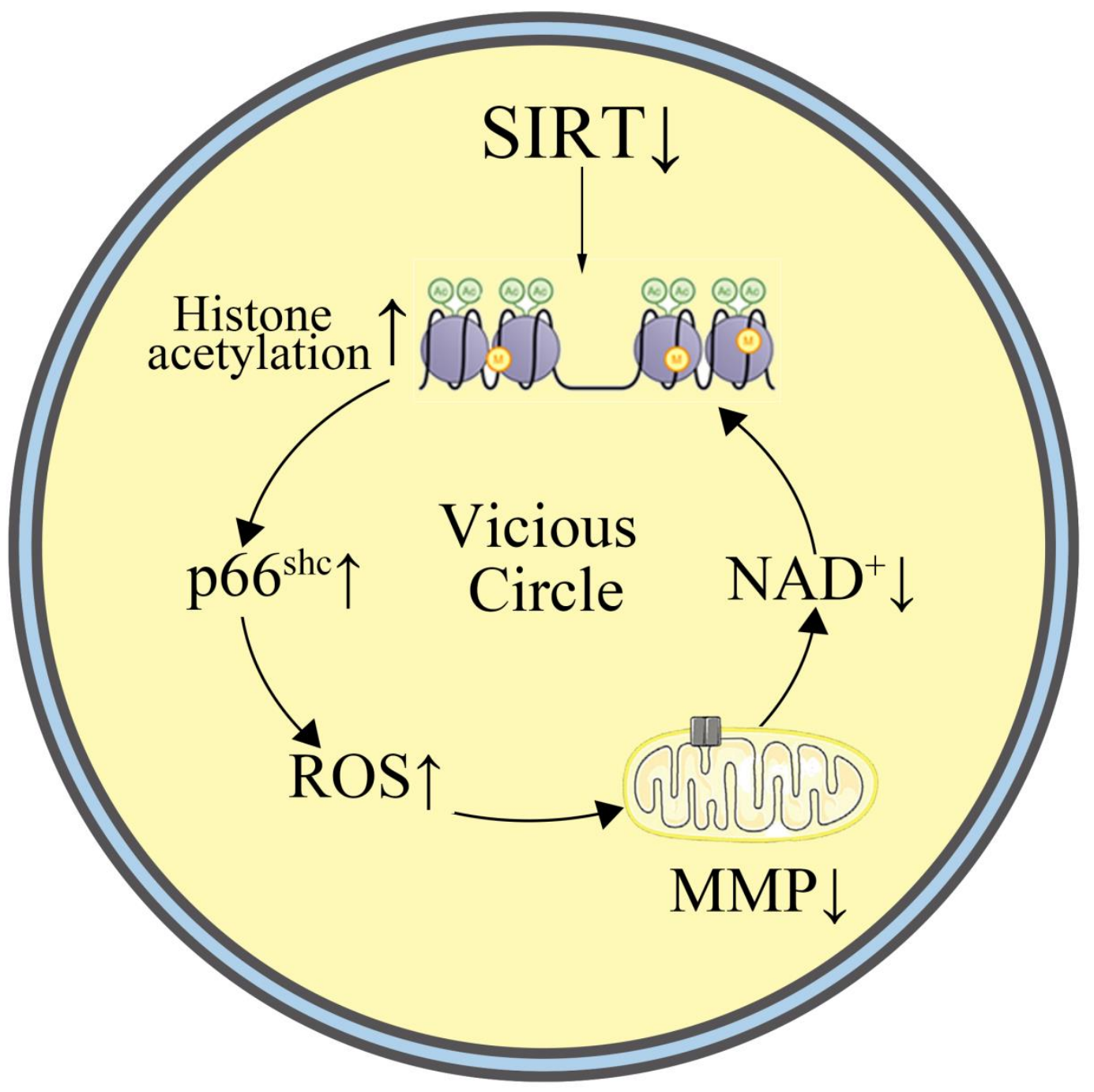

Fig. 9 the cerebrovascular endothelial cell damage memory vicious circle. 


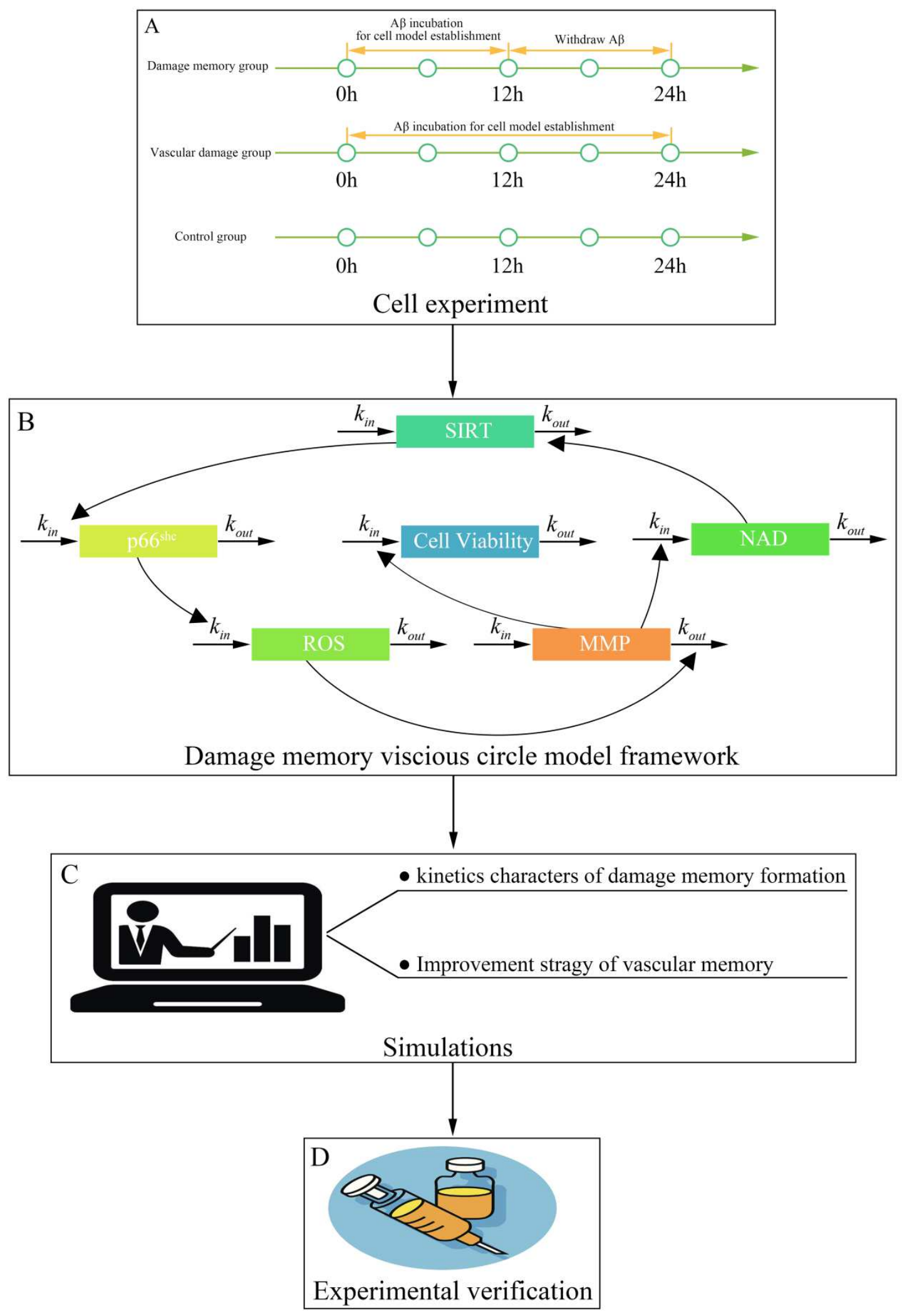

Fig. 10 the framework of this study 


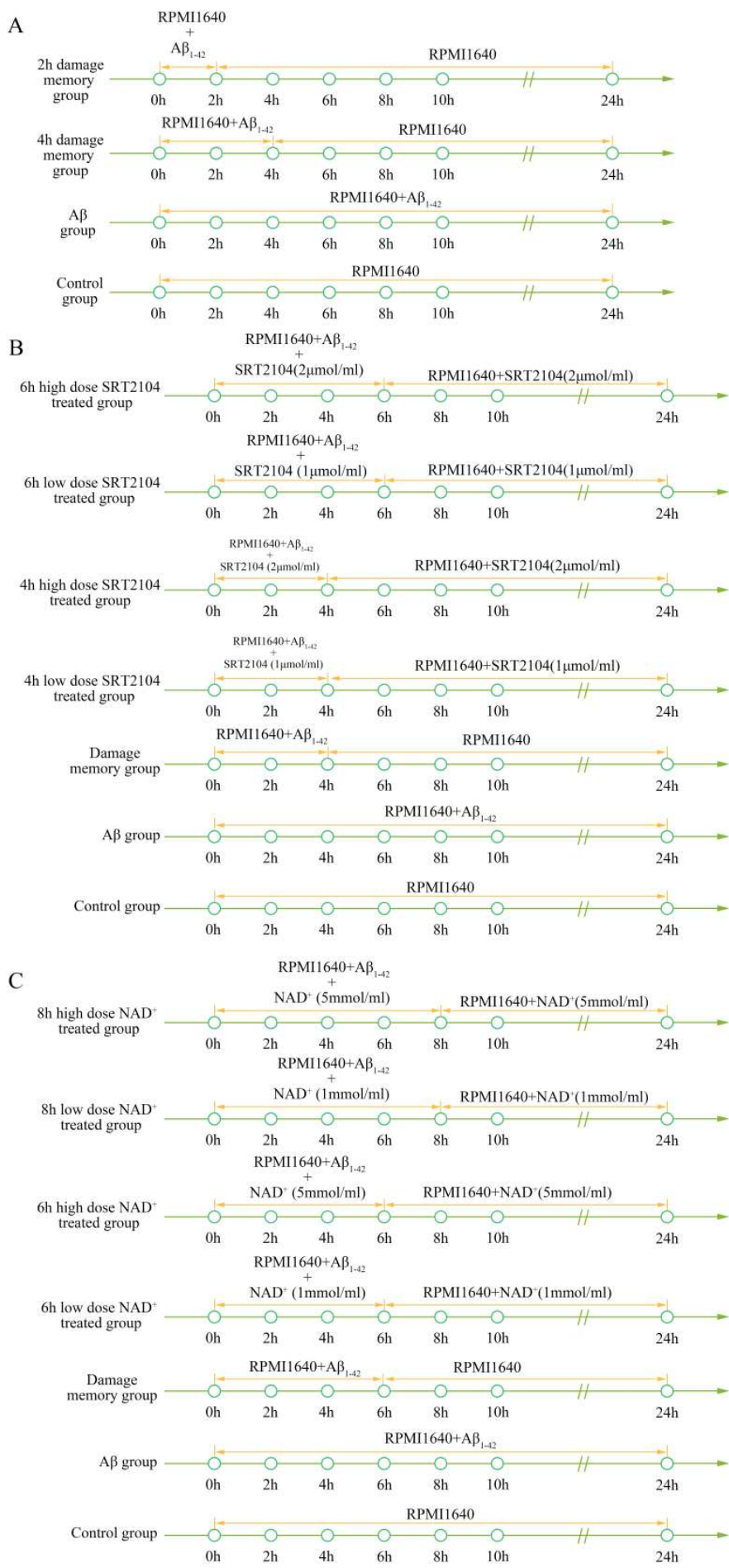

Fig. 11 A: experimental protocol for determining time of cerebrovascular endothelial cell damage memory formation. B: experimental protocol for evaluating the effect of SRT2104 on delaying the formation of cerebrovascular endothelial cell damage memory. C: experimental protocol for evaluating the effect of $\mathrm{NAD}^{+}$supplement on delaying the formation of cerebrovascular endothelial cell damage memory. 
Figures
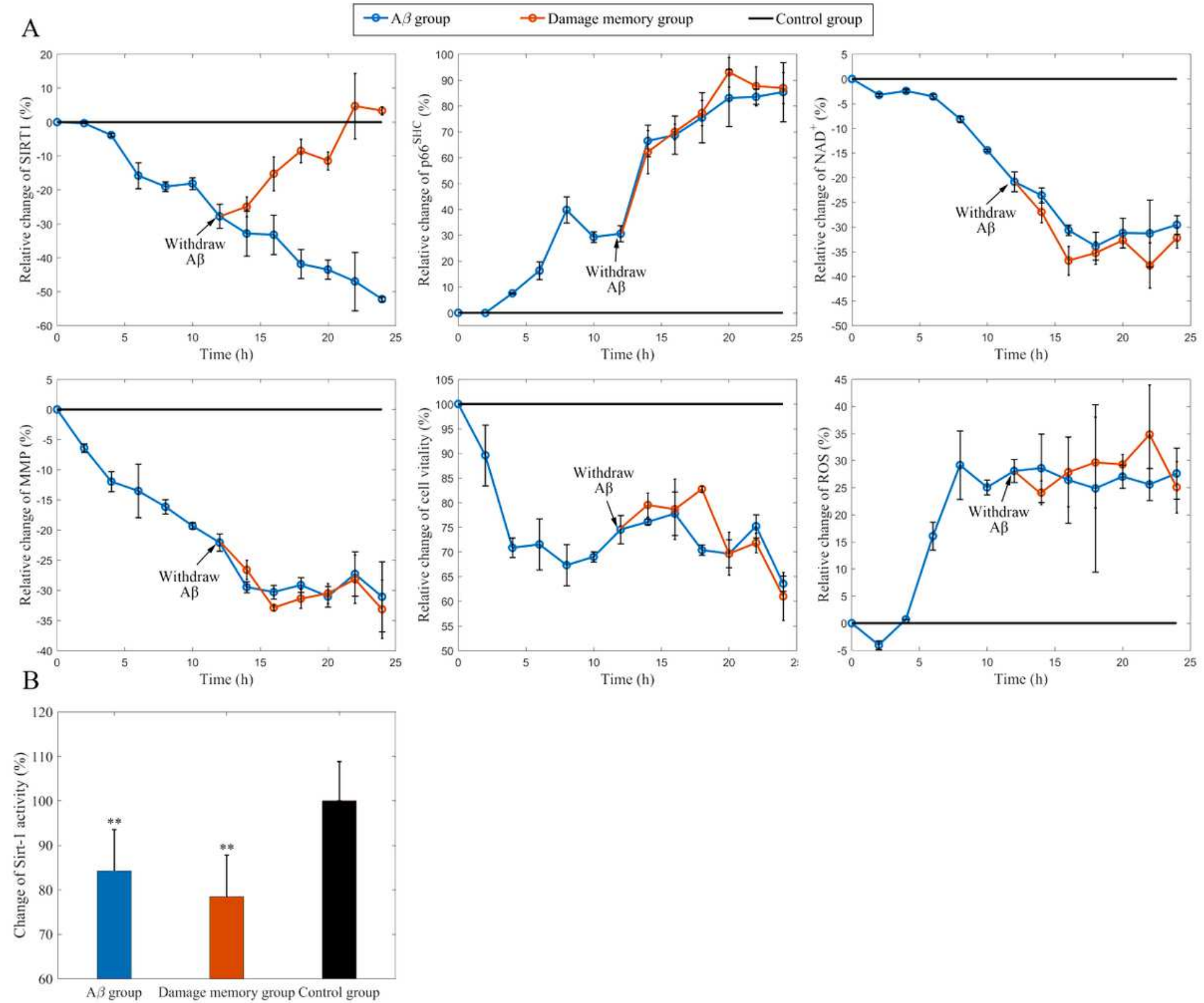

Figure 1

A: the time course of relative change of sirt-1, p66SHC, NAD+, ROS, MMP, and cell vitality compared to the control group. The black line represent the control group level which is normalized to $100 \%$. The blue line represent $A \beta$ group level. The red line represent the damage memory group. $B$ : the levels of sirt- 1 activity in damage memory group, $A \beta$ group and control group. 
A

C
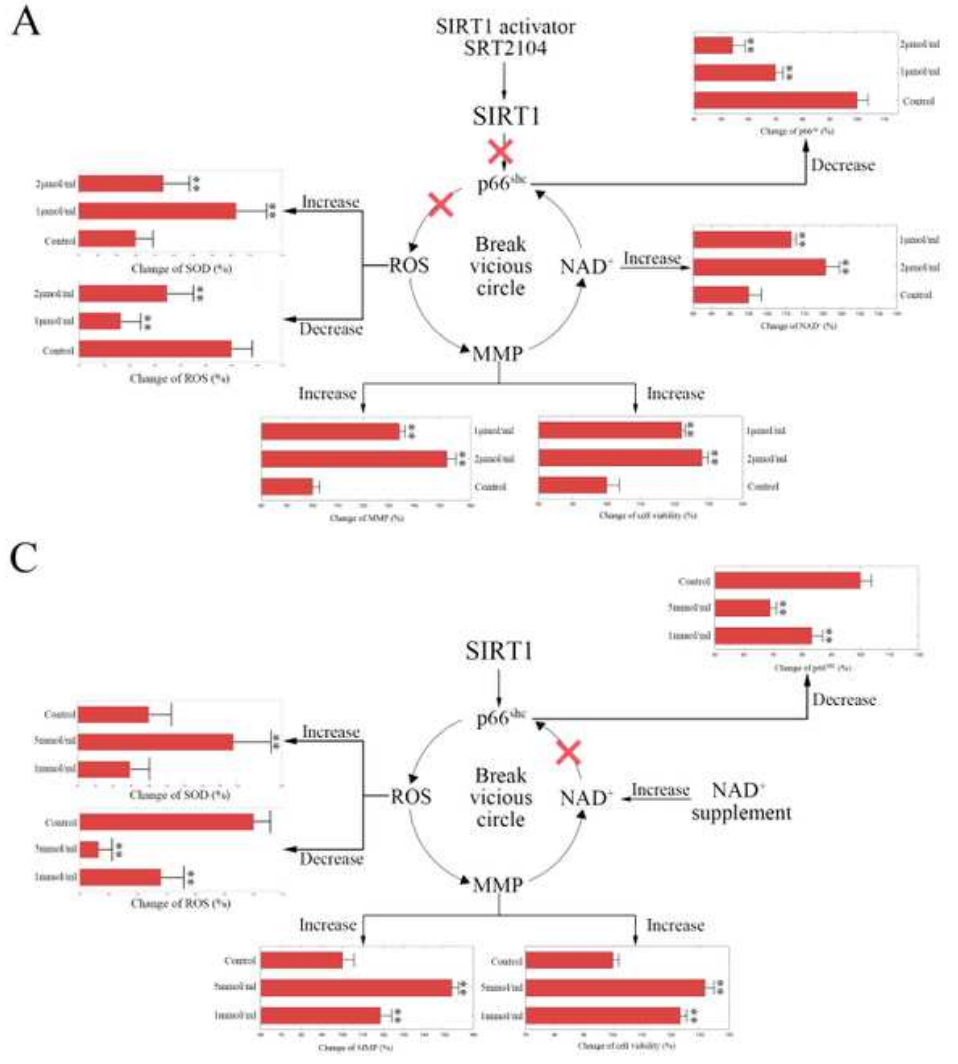

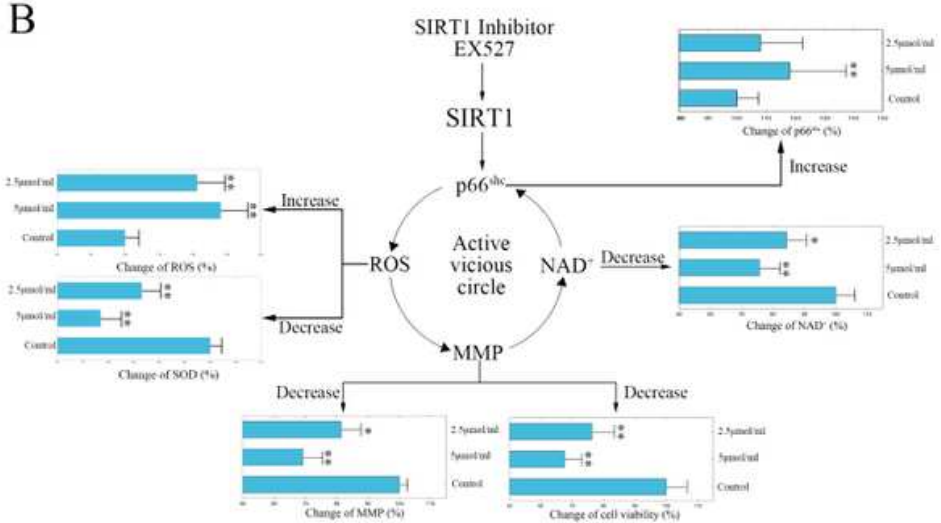

\section{Figure 2}

A: the change of p66SHC, NAD+, MMP, ROS, Mn-SOD and cell vitality in SRT2104 treated hCMEC/D3 cell. The control group data is normalized to $100 \%$. B: the change of p66SHC, NAD+, MMP, ROS, Mn-SOD and cell vitality in EX527 treated hCMEC/D3 cell. The control group data is normalized to 100\%. C: the change of p66SHC, MMP, ROS, Mn-SOD and cell vitality in NAD+ supplement treated hCMEC/D3 cell. The control group data is normalized to $100 \%$. ** $p<0.01$ * $p<0.05$ 
A
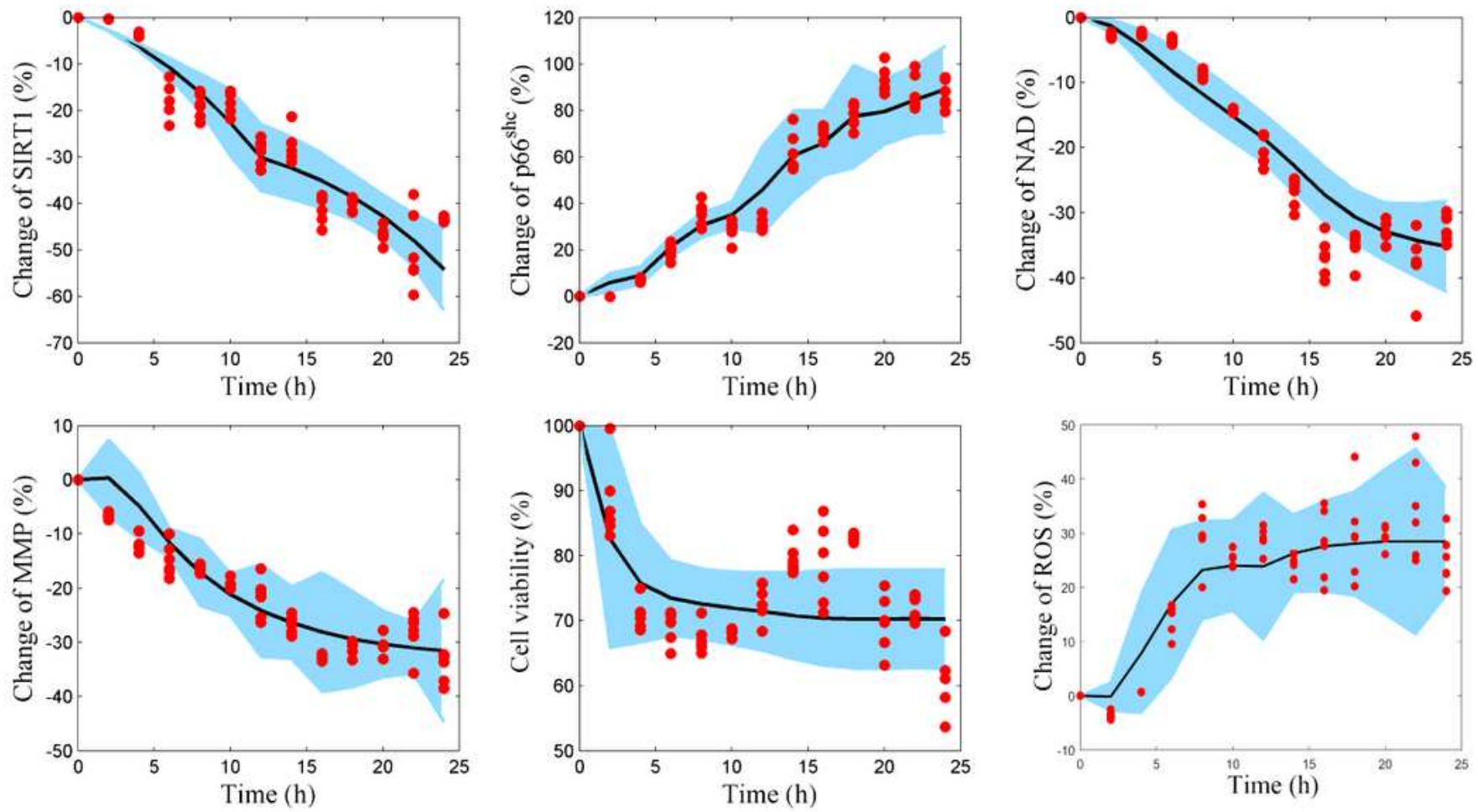

B
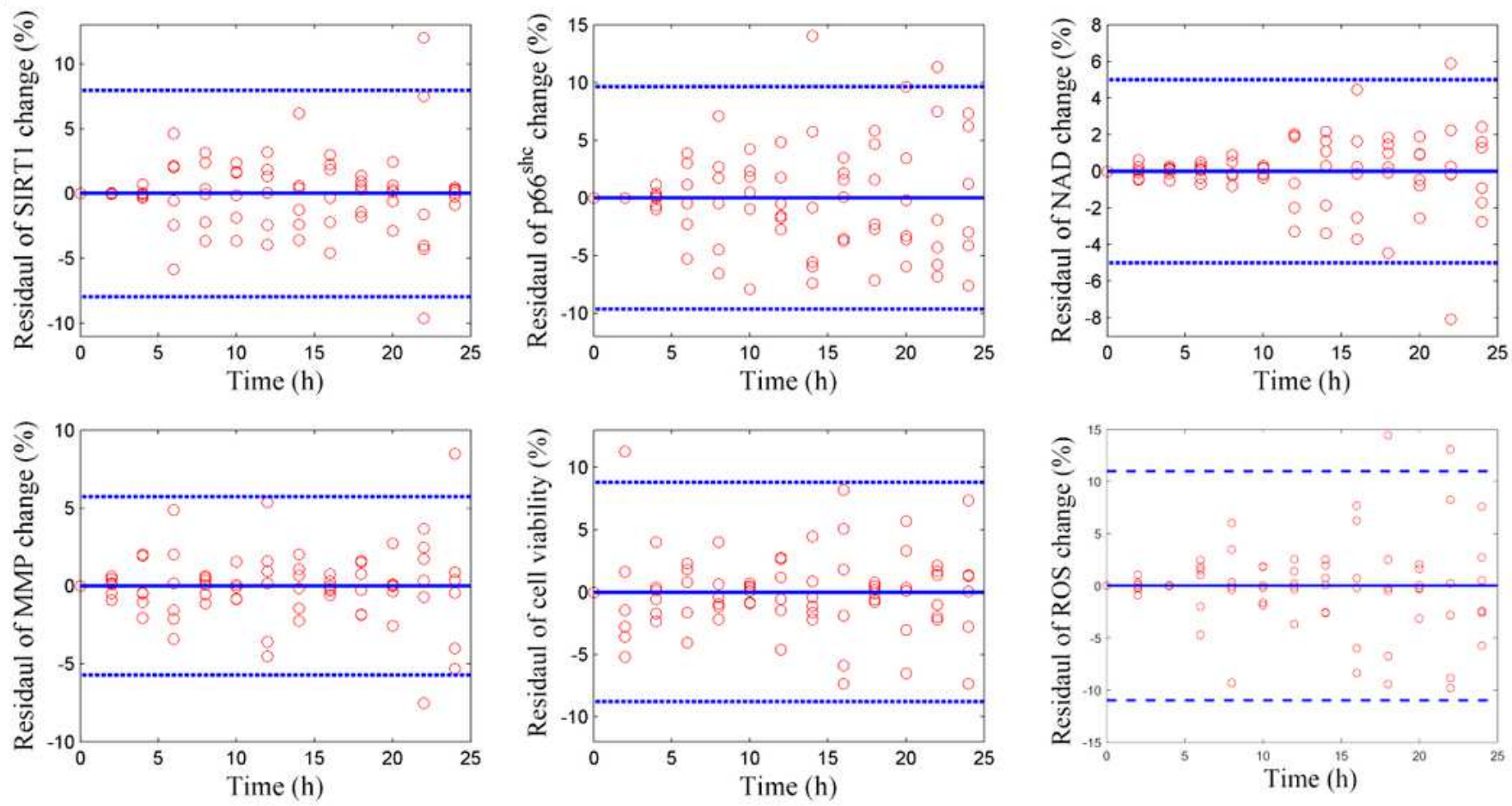

\section{Figure 3}

A: visual predicted check (VPC) for sirt-1, p66SHC, ROS, NAD+, MMP, and cell vitality. The shaded area represents the $95 \%$ confidence interval of the simulated median value. The line represents the median value of observed value. The red scatters represent observed values. B: scatter plots of predicted residuals vs. time for sirt- 1 , p66SHC, ROS, NAD+, MMP, and cell vitality. 

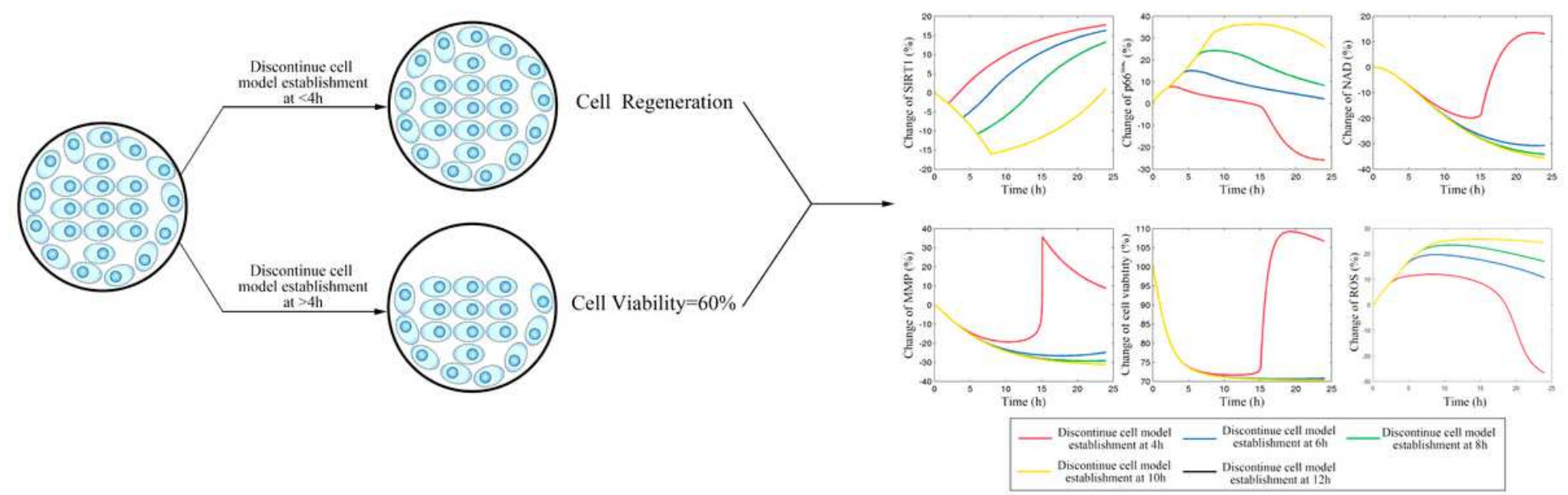

\section{Figure 4}

the simulation results for scenario I which investigate the time of cerebrovascular endothelial cell damage memory formation. 

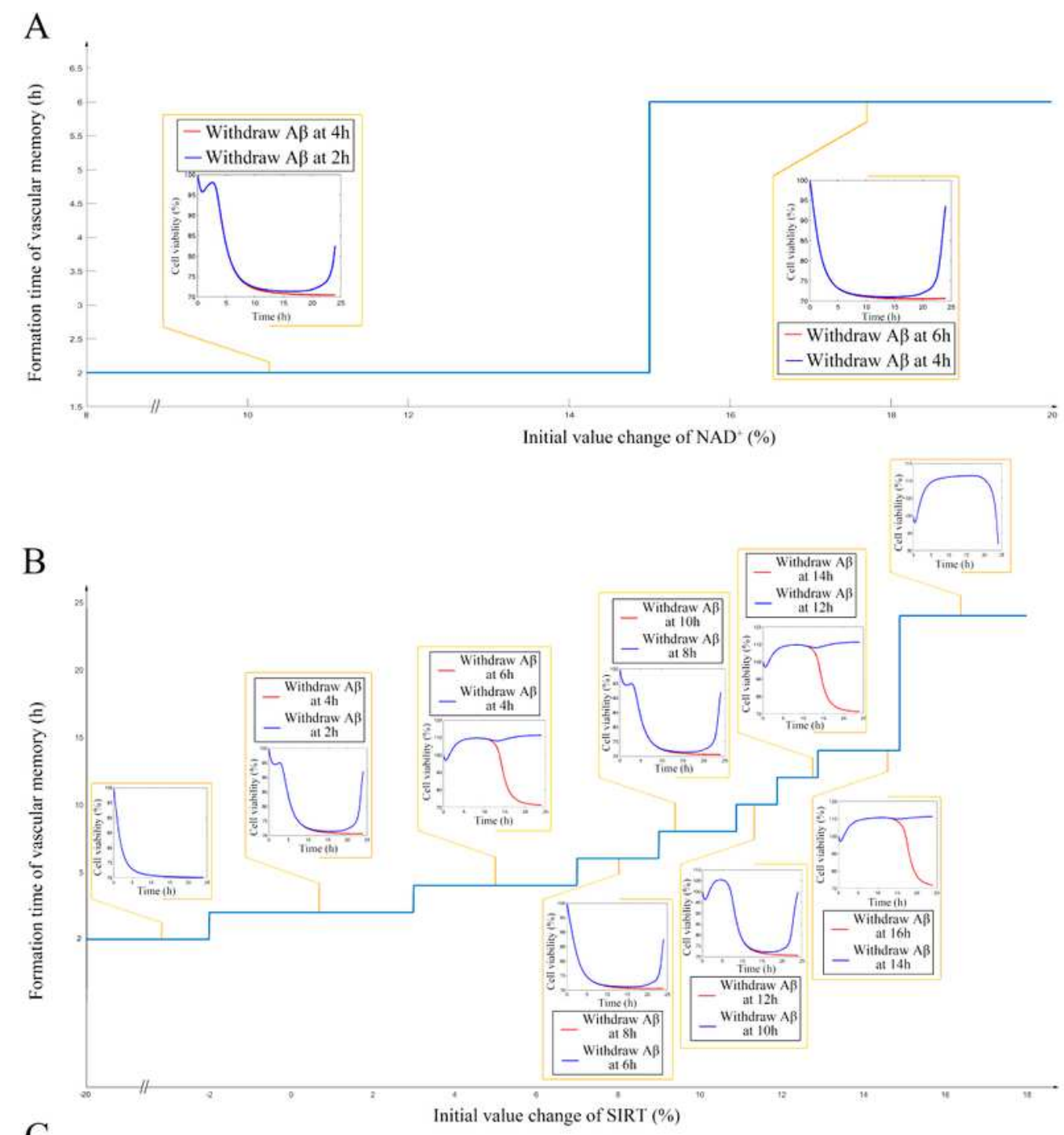

C

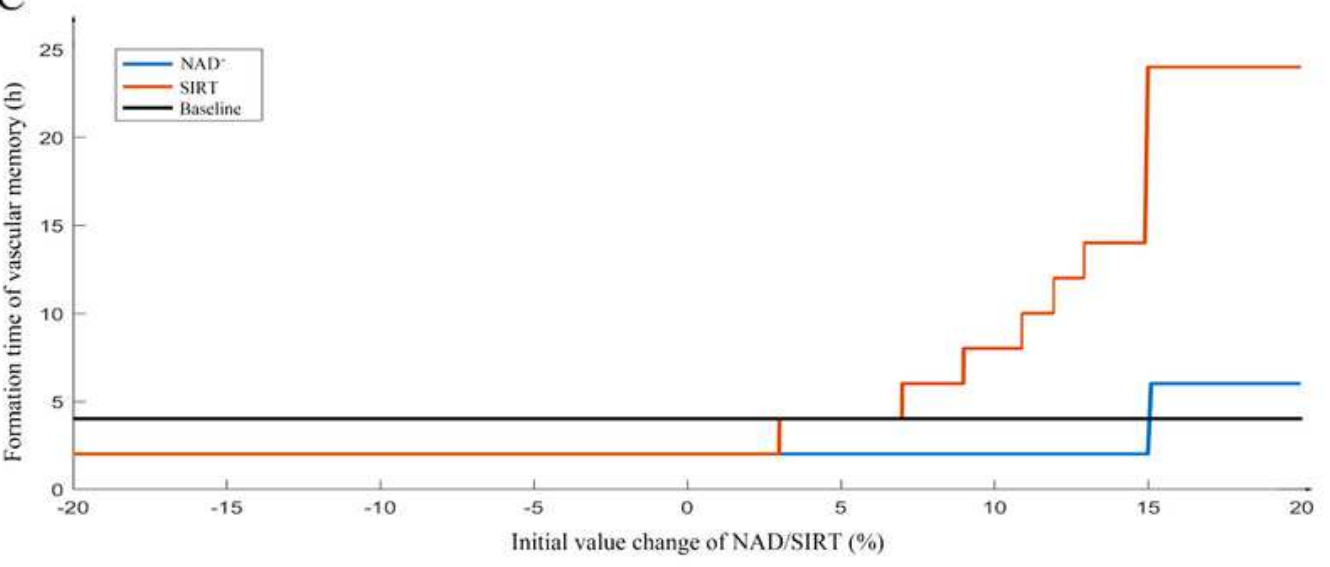

\section{Figure 5}

A: the impact of different levels of NAD+ on the cerebrovascular endothelial cell damage memory formation time. B: the impact of different levels of sirt- 1 on the cerebrovascular endothelial cell damage memory formation time. C: the summary plot of the impact of different levels of sirt-1 and NAD+ on the cerebrovascular endothelial cell damage memory formation time. 


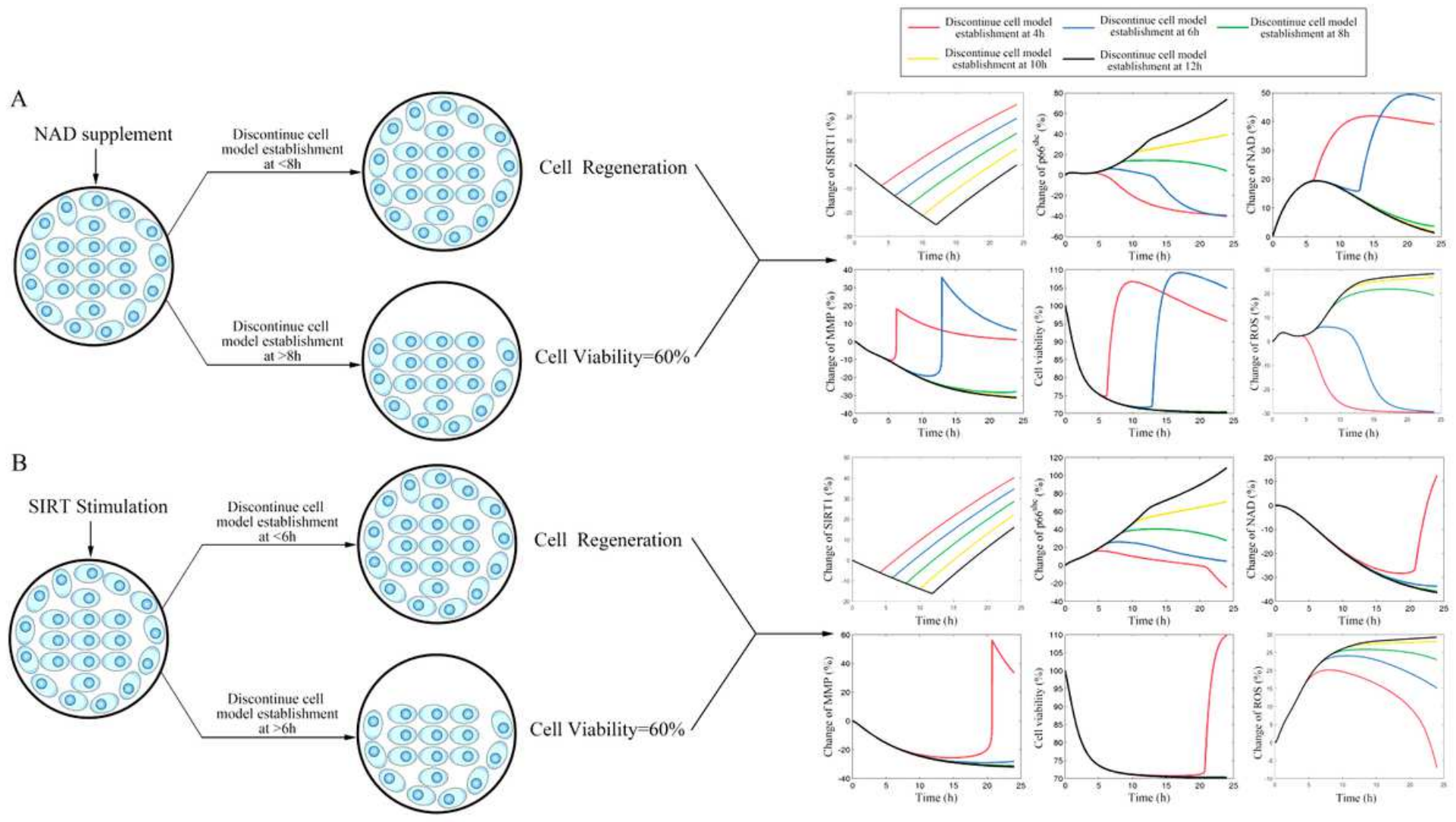

\section{Figure 6}

A: the simulation for change of sirt-1, p66SHC, ROS, NAD+, MMP, and cell vitality in NAD+ supplement treated cells. B: the simulation for change of sirt-1, p66SHC, ROS, NAD+, MMP, and cell vitality in sirt-1 activator treated cells. 


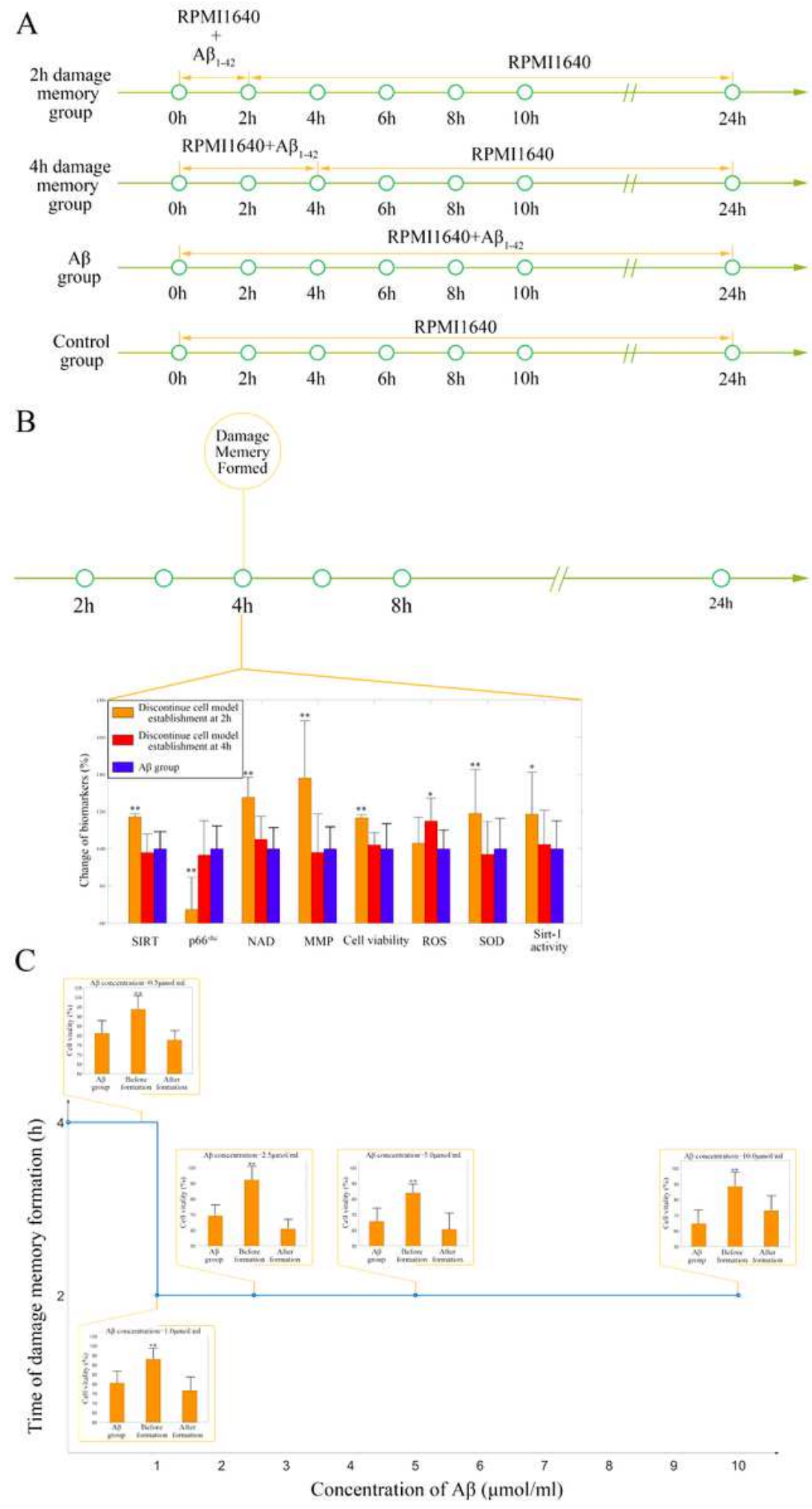

\section{Figure 7}

A: experimental protocol for determining time of cerebrovascular endothelial cell damage memory formation. B: the experimental validation of cerebrovascular endothelial cell damage memory formation time. $C$ : the damage memory formation time with different concentration of $A \beta$ incubation. 
A

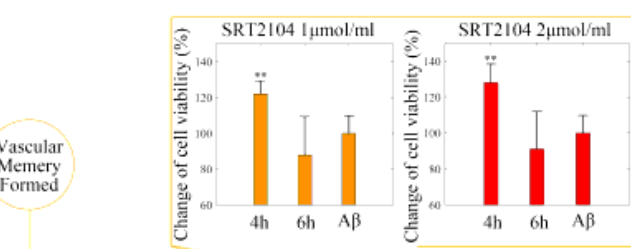

$\longrightarrow$

$2 \mathrm{~h}$

$4 \mathrm{~h}$

$6 \mathrm{~h}$

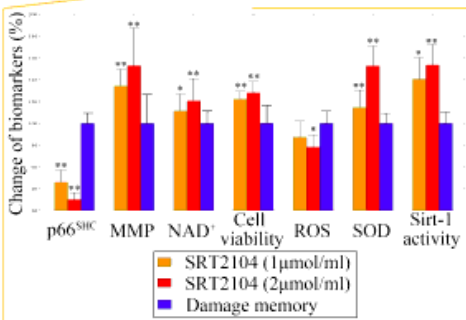

$\mathrm{C}$
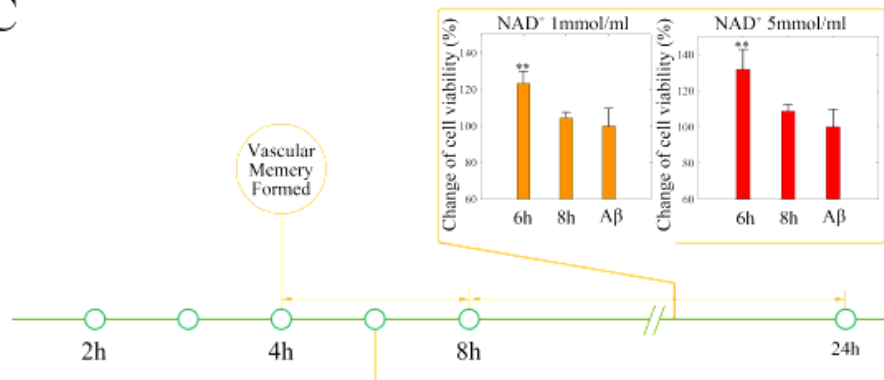

$8 \mathrm{~h}$

24h

$\mathrm{E}$
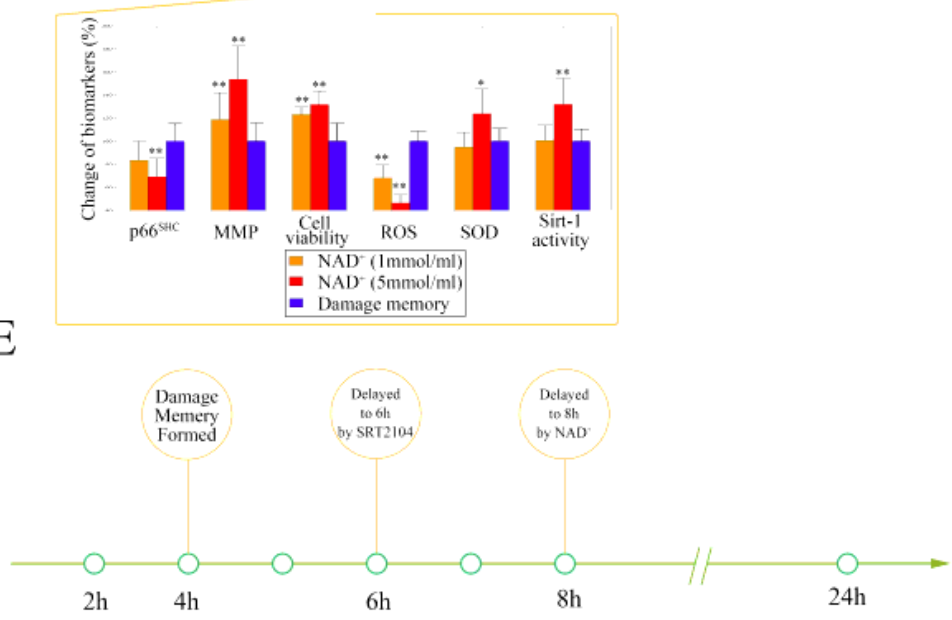

B

RPMI $1640+\Lambda \beta_{1-42}$

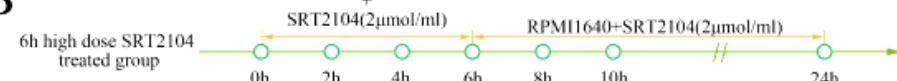
treated aroup

$\begin{array}{llllll}2 \mathrm{~h} & 4 \mathrm{~h} & 6 \mathrm{~h} & 8 \mathrm{~h} & 10 \mathrm{~h} & 24 \mathrm{~h}\end{array}$

RPMI $1640+\mathrm{A} \beta_{1+2}$

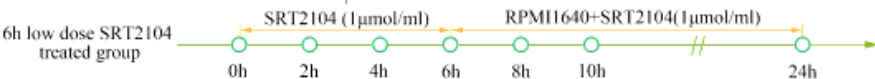

RPMU1640+AB.

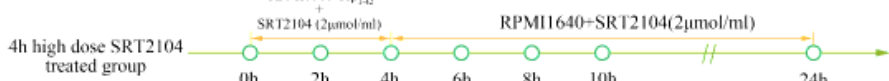

(0) 2 h

SRT2104 (1 1 mmol/ml) $\quad$ RPMII $640+$ SRT2 $104(1 \mu \mathrm{mol} / \mathrm{ml})$

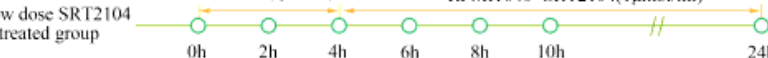

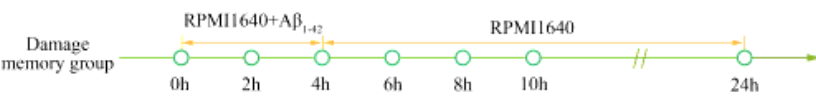
RPMII $640+\mathrm{A} \beta_{142}$
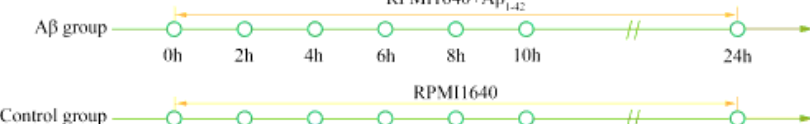

$\mathrm{D}$
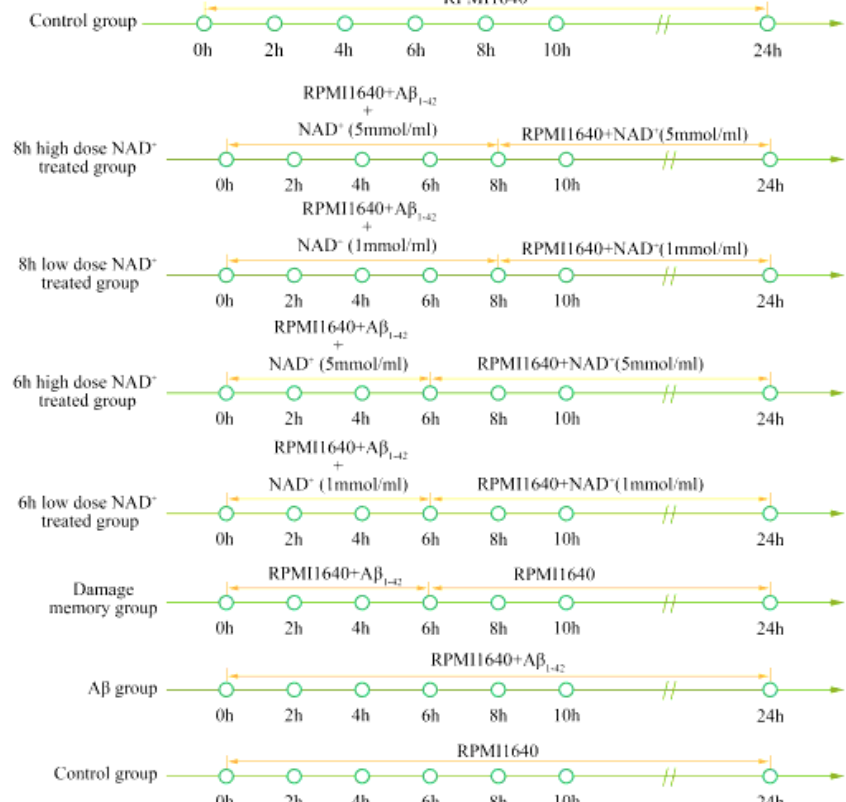

\section{Figure 8}

A: the effect of SRT2104 on delaying the formation of cerebrovascular endothelial cell damage memory formation. B: experimental protocol for evaluating the effect of SRT2104 on delaying the formation of cerebrovascular endothelial cell damage memory. C: the effect of NAD+ supplement on delaying the formation of cerebrovascular endothelial cell damage memory formation. D: experimental protocol for evaluating the effect of NAD+ supplement on delaying the formation of cerebrovascular endothelial cell damage memory. E: summary of the effect of SRT2104 and NAD+ supplement on delaying the formation of cerebrovascular endothelial cell damage memory formation. 


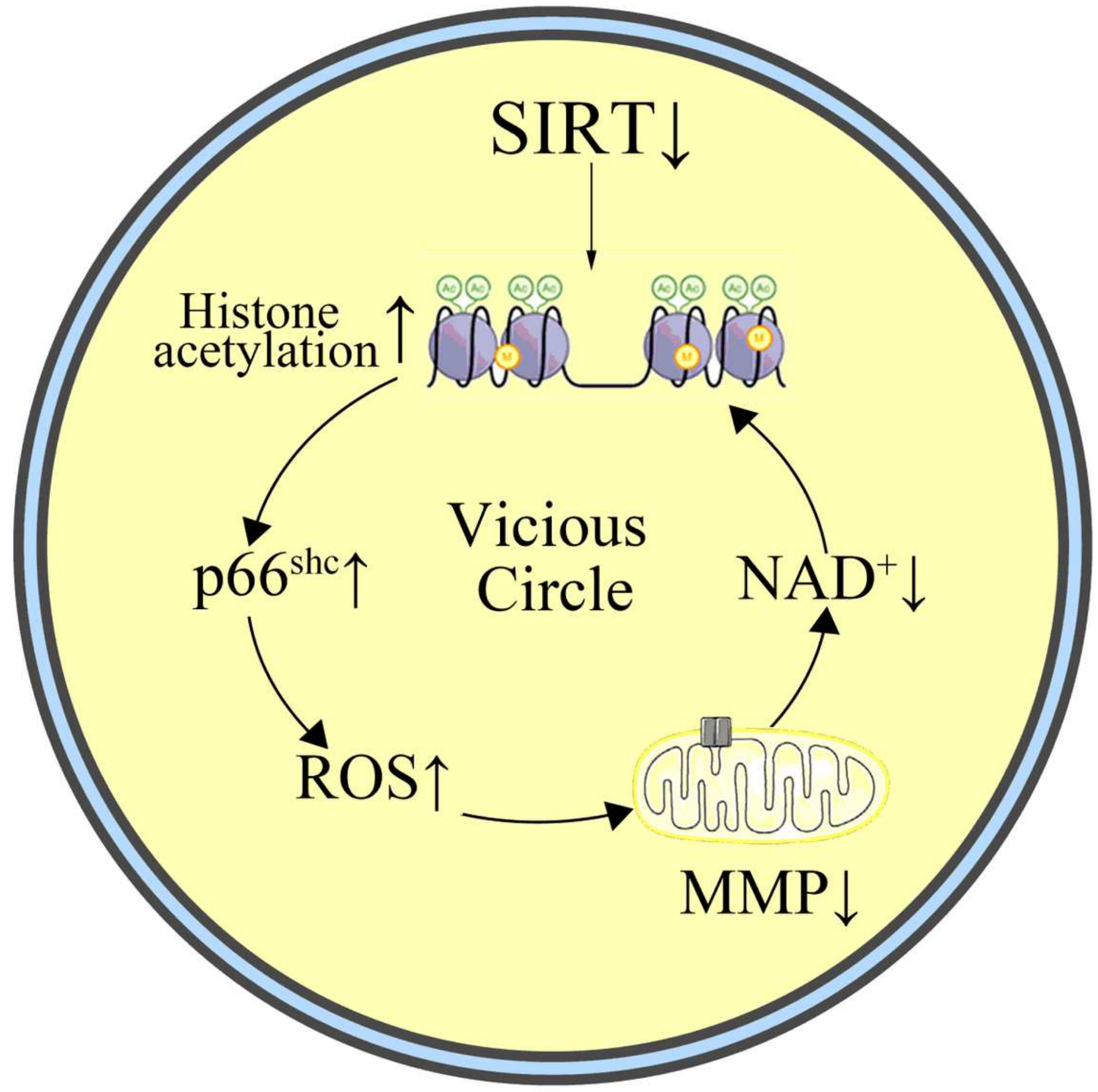

Figure 9

the cerebrovascular endothelial cell damage memory vicious circle. 


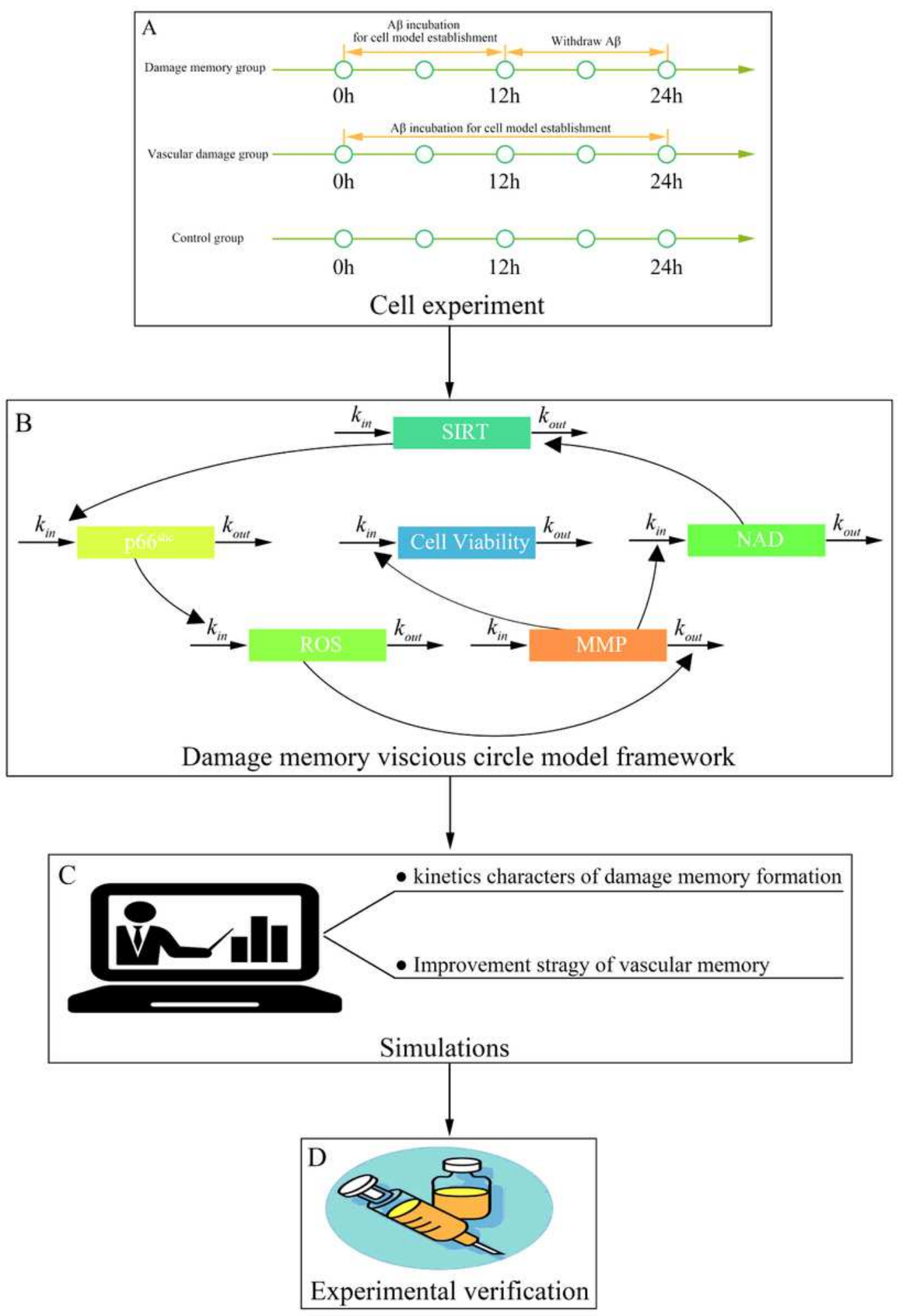

Figure 10

the framework of this study 


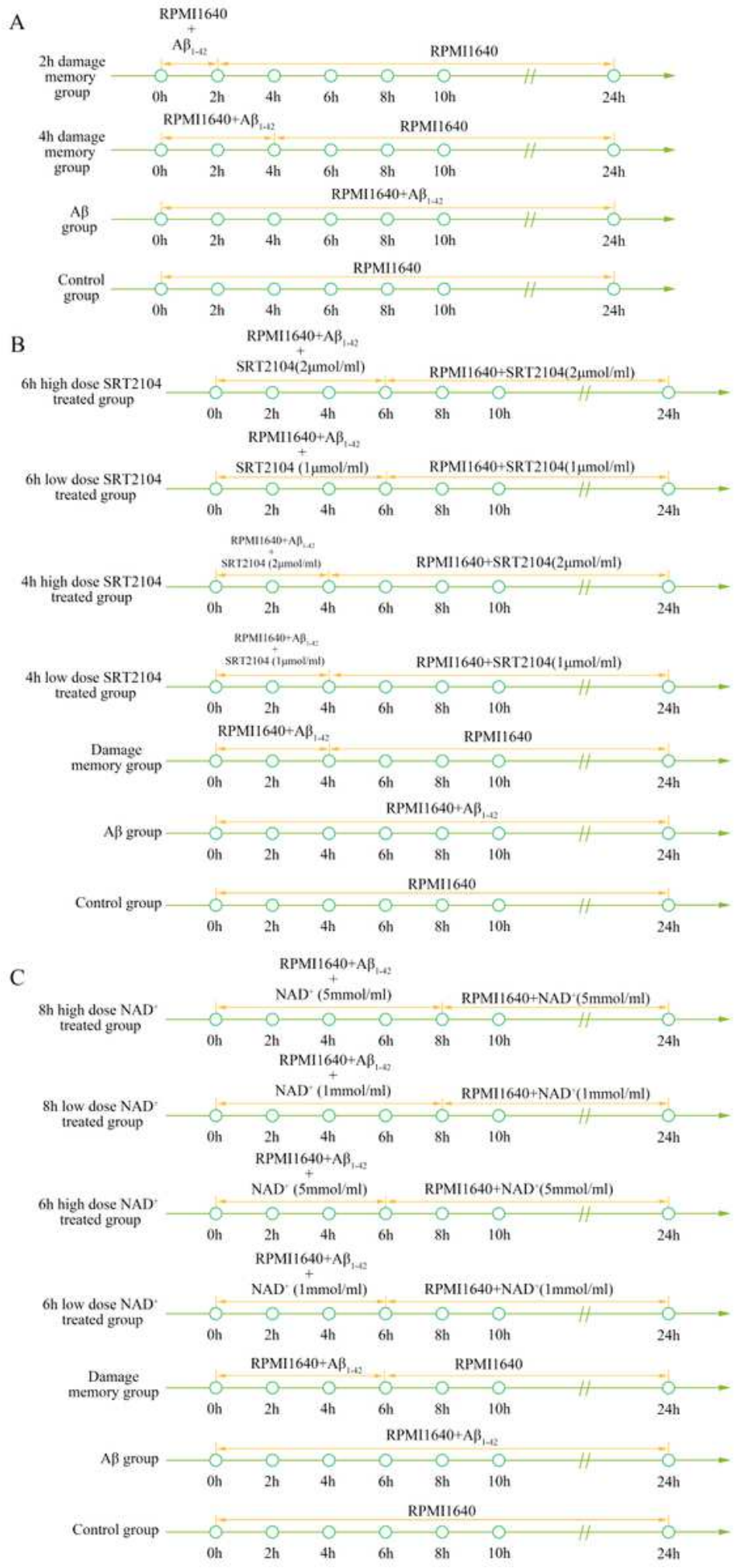

\section{Figure 11}

A: experimental protocol for determining time of cerebrovascular endothelial cell damage memory formation. B: experimental protocol for evaluating the effect of SRT2104 on delaying the formation of cerebrovascular endothelial cell damage memory. C: experimental protocol for evaluating the effect of $\mathrm{NAD}+$ supplement on delaying the formation of cerebrovascular endothelial cell damage memory. 


\section{Supplementary Files}

This is a list of supplementary files associated with this preprint. Click to download.

- Supplementarydatav2.docx 